\title{
Review
}

\section{NOV (nephroblastoma overexpressed) and the CCN family of genes: structural and functional issues}

B Perbal

\begin{abstract}
The CCN family of genes presently consists of six distinct members encoding proteins that participate in fundamental biological processes such as cell proliferation, attachment, migration, differentiation, wound healing, angiogenesis, and several pathologies including fibrosis and tumorigenesis. Whereas CYR61 and CTGF were reported to act as positive regulators of cell growth, NOV (nephroblastoma overexpressed) provided the first example of a $\mathrm{CCN}$ protein with negative regulatory properties and the first example of aberrant expression being associated with tumour development. The subsequent discovery of the ELM1, rCOP1, and WISP proteins has broadened the variety of functions attributed to the CCN proteins and has extended previous observations to other biological systems. This review discusses fundamental questions regarding the regulation of $\mathrm{CCN}$ gene expression in normal and pathological conditions, and the structural basis for their specific biological activity. After discussing the role of nov and other CCN proteins in the development of a variety of different tissues such as kidney, nervous system, muscle, cartilage, and bone, the altered expression of the $\mathrm{CCN}$ proteins in various pathologies is discussed, with an emphasis on the altered expression of nov in many different tumour types such as Wilms's tumour, renal cell carcinomas, prostate carcinomas, osteosarcomas, chondrosarcomas, adrenocortical carcinomas, and neuroblastomas. The possible use of nov as a tool for molecular medicine is also discussed. The variety of biological functions attributed to the $\mathrm{CCN}$ proteins has led to the proposal of a model in which physical interactions between the amino and carboxy portions of the CCN proteins modulate their biological activity and ensure a proper balance of positive and negative signals through interactions with other partners. In this model, disruption of the secondary structure of the CCN proteins induced by deletions of either
\end{abstract}

terminus is expected to confer on the truncated polypeptide constitutive positive or negative activities. (F Clin Pathol: Mol Pathol 2001;54:57-79)

Keywords: cancer; differentiation; signalling; development; angiogenesis; fibrosis; ctgf; cyr61; wisp; CCN

The regulation of cellular growth, differentiation, and death is central to a myriad of biological processes that govern the appearance, maintenance, and termination of life.

Although many genes whose products are reported to play a key role in cell growth control have been described, several basic regulatory circuits involve proteins yet to be identified.

The discovery of three structurally related genes whose expression was modulated by growth factors and altered in cancer cells has led to the recognition of a new family of cell growth regulators with unique biological properties.

Bork $^{1}$ first proposed that these genes should be designated the CCN family of genes, which stands for Cyr61 (cystein rich protein), Ctgf (connective tissue growth factor), and Nov (nephroblastoma overexpressed gene). The existence of this family of genes has recently been reinforced by the discovery of three new members (see below).

For many years, the CCN proteins seemed not to share much more than their strikingly conserved primary structure and no physiological or biological properties had been clearly assigned to them.

The bulk of the recent results presented at the first international workshop on the CCN family of genes and the increasing pace at which papers are being published in this field point to the increased attention being focused on these proteins. Their roles are being clearly established in fundamental biological processes such as cell proliferation, attachment, migration, and differentiation, wound healing, angiogenesis, and several pathologies including fibrosis and tumorigenesis. Furthermore, it appears that in spite of their highly conserved structure, these proteins display nonredundant functions, which are apparently 


\begin{tabular}{|c|c|c|}
\hline $\begin{array}{l}\text { cyr61 } \\
(1 \mathrm{p} 22.3)\end{array}$ & Cystein rich 61 & $\begin{array}{l}\text { CEF10 (chicken embryo fibroblasts) (Ck) } \\
\beta I G 1 \text { (TGF } \beta \text { induced gene) cyr61 (Mu) }\end{array}$ \\
\hline $\begin{array}{l}\operatorname{ctg} f \\
(6 q 23.1)\end{array}$ & $\begin{array}{l}\text { Connective tissue } \\
\text { growth factor }\end{array}$ & $\begin{array}{l}\text { Ctgf (Ck) ctgf }(\mathrm{Sw}) \operatorname{ctgf}(\mathrm{Xn}) \\
\text { blG2 (TGF } \beta \text { induced gene) (Mu) } \\
\text { Fisp } 12 \text { (fibroblast inducible secreted protein) (Mu) }\end{array}$ \\
\hline $\begin{array}{l}\text { nov } \\
(8 \mathrm{q} 24.1)\end{array}$ & $\begin{array}{l}\text { Nephroblastoma } \\
\text { overexpressed }\end{array}$ & $\operatorname{nov}(\mathrm{Ck}) \operatorname{novM}(\mathrm{Mu})$ nov $(\mathrm{Sw})$ nov $(\mathrm{Xn})$ \\
\hline $\begin{array}{l}\text { WISP-1 } \\
\text { (8q24.1-24.3) }\end{array}$ & $\begin{array}{l}\text { Wnt-1 induced } \\
\text { secreted protein }\end{array}$ & $\begin{array}{l}\text { Elm1 (expressed in low metastatic type } 1 \text { cells) (Mu) } \\
\text { Wisp } 1(\mathrm{Mu})\end{array}$ \\
\hline $\begin{array}{l}\text { WISP-2 } \\
(20 q 12-13)\end{array}$ & $\begin{array}{l}\text { Wnt-1 induced } \\
\text { secreted protein }\end{array}$ & $\begin{array}{l}\text { rCop-1 (expression lost after transformation) (Mu) } \\
\text { HICP (heparin induced CCN-like protein) } \\
\text { Wisp } 2 \text { (Mu) }\end{array}$ \\
\hline $\begin{array}{l}\text { WISP-3 } \\
(6 q 23.1)\end{array}$ & $\begin{array}{l}\text { Wnt-1 induced } \\
\text { secreted protein }\end{array}$ & \\
\hline
\end{tabular}

required at different locations and at different times along the same biological pathways.

Understanding the structural and functional bases for the molecular diversity of the CCN family is an important challenge. It will set the stage for understanding the role of these genes in the control of cellular proliferation, differentiation, and death, thereby allowing the use of these genes and proteins in modern biomedical technologies for early diagnosis and treatment.

Because recent publications have dealt in detail with the description of the CCN genes and corresponding proteins, ${ }^{2-4}$ this review will deal with some fundamental questions regarding the expression of $\mathrm{CCN}$ proteins in normal and pathological conditions, and the structural basis for their specific biological activity, with an emphasis on studies performed on the nov gene in my laboratory.

\section{Isolation of the $\mathrm{CCN}$ genes}

The CCN family of genes presently consists of six distinct members in the human (fig 1), the orthologues of which have been described in several different species ranging from xenopus to rodents.

The way in which the CCN genes were isolated might provide valuable information for understanding their differential expression and biological properties. The different strategies that have led to the isolation of CCN genes include: subtractive hybridisation and differential display of RNAs whose expression is affected in normal cells stimulated to grow by serum, growth factors, and viruses, or in tumour cells as compared with their normal counterparts.

The differential screening strategies are based on the fact that RNA species are under represented or lacking in one of the two situations analysed. Although most authors attribute increased RNA values to stimulation of transcription, it is important to keep in mind that RNA metabolism can be affected dramatically by the events that lead to transformation or induction of proliferation in response to viral infection and growth factors. Only in a few instances was it possible to check whether increased or decreased gene expression was indeed responsible for the differential levels of transcripts detected, by means of nuclear run on transcription assays. This aspect must be approached with extreme caution because it has a pronounced impact on our way of thinking when analysing the biological properties of potential regulatory molecules, such as CCN proteins, whose expression is developmentally regulated in a spatiotemporal way.

GENES THAT WERE ISOLATED ON THE BASIS OF THEIR DIFFERENTIAL EXPRESSION IN QUIESCENT AND SERUM STIMULATED CELLS

Under starvation conditions (incubation in low serum concentration), confluent cells stop growing and reach the G0 state of the cell cycle. G1 phase re-entry of the starved cells upon treatment with serum triggers the stimulation of immediate early genes, whose expression proceeds shortly after serum stimulation, without the need for de novo protein synthesis (the immediate early terminology was used by comparison with the ordered expression of viral genes upon infection of eukaryotic cells). Characterisation of these immediate genes provided important clues as to the type of genes responsible for the regulation of master switches involved in the control of cell growth.

This experimental approach, which had previously led to the discovery of a variety of signalling proteins and transcription factors, led to the isolation of the murine cyr61 and fisp12 genes.

Fibroblastic cells of different origins have been used to analyse gene expression during serum induced G0/G1 transition. Differential screening of a cDNA library prepared from serum stimulated mouse BALB/c3T3 fibroblasts led to the isolation of cyr61, which encodes a secreted 379 residue polypeptide of apparent molecular mass $42 \mathrm{kDa},{ }^{5}$ whereas a similar strategy performed with mouse NIH3T3 cells led to the isolation of fisp12, which encodes a secreted 348 residue polypeptide of $37 \mathrm{kDa}{ }^{6}$ The early expression of these genes in the cell cycle without the need of prior protein synthesis categorised them as immediate early genes.

Early studies established that immediate early genes were expressed transiently and were either required for the G0-G1 transition or for G1 progression to $S$ phase. In the first group, c-fos expression is induced between 20 and 90 minutes and decreases to undetectable levels after two hours, whereas in the second group, c-myc expression is induced between 45 minutes and three hours and is detectable up to six hours after serum stimulation.

Both cyr61 and fisp12 showed the same rapid induction pattern, starting 30 minutes after serum stimulation and peaking between one and two hours after stimulation. In both cases, short half life (30 minutes for cyr61, 10-15 minutes for fisp12) RNA species were produced, and sustained expression was observed over several hours after the addition of serum to starved cells. As reported for other immediate early genes, the decrease in mRNA values requires protein synthesis.

Therefore, it appears that cyr61 and fisp 12 represent a new class of genes that are induced 


$\square$ fos $\quad \square$ myc $\quad \square$ cyr61/ctgf $\quad$ cyr61 $\square$ elm1 $\square$ nov $\quad \square$ cop1

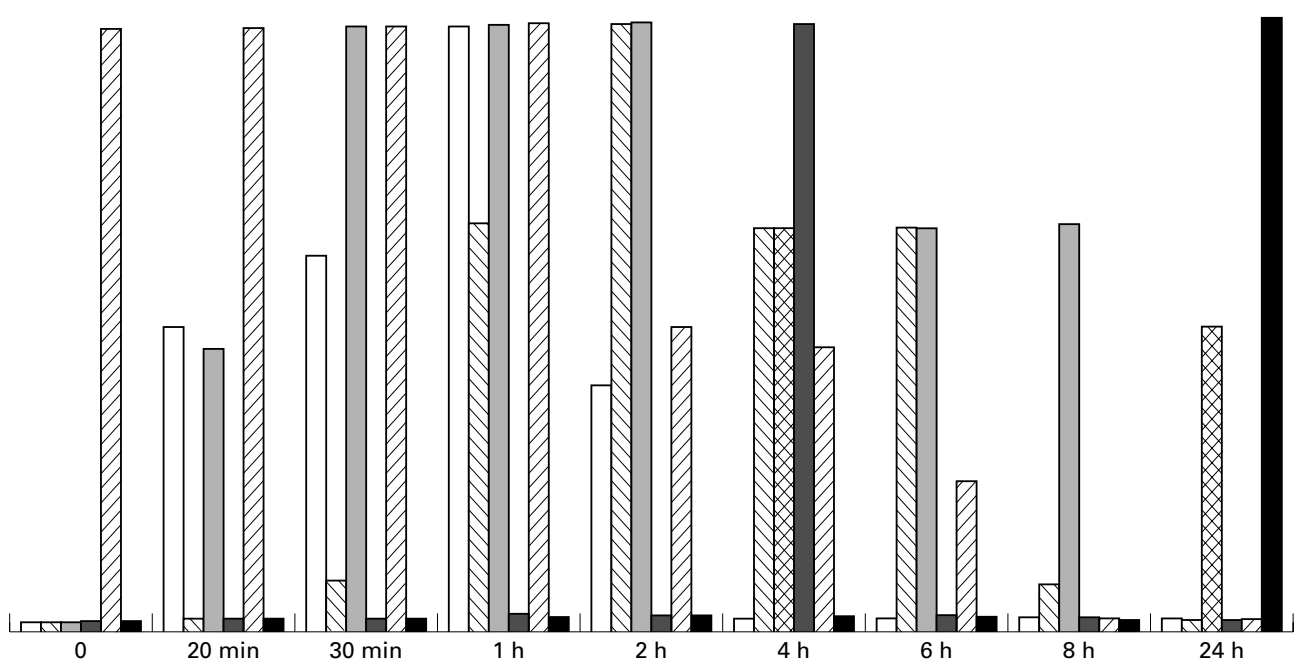

Figure 2 Kinetics of CCN gene expression upon stimulation of cell growth.

in the sequential cellular response to mitogenic signals. The CYR61 and FISP12 proteins are likely to be required for a relatively long period during the progression through the G1 phase.

It is worth pointing out that a second burst of cyr61 RNA synthesis was seen between six and 10 hours after serum stimulation, suggesting that the expression of this protein might also be required at a later stage of cell cycle progression (fig 2).

GENES THAT WERE IDENTIFIED ON THE BASIS OF THEIR INCREASED EXPRESSION IN CELLS TREATED BY TGF $\beta 1$

A considerable number of studies performed with transforming growth factor $\beta$ (TGF $\beta$ ) have established the key role of this signalling molecule in the regulation of cell growth and differentiation.

For many years, it has been proposed that the biological effects of TGF $\beta$ are mediated by a variety of downstream effectors. To identify genes in which transcription was affected by TGF $\beta 1$, a cDNA library was prepared from AKR-2B mouse embryo fibroblasts grown to $90 \%$ confluency and treated with cycloheximide before incubation for six hours in the presence of $10 \mathrm{ng} / \mathrm{ml}$ TGF $\beta 1$. Differential screening of this library with labelled cDNA probes obtained from untreated and TGF $\beta 1$ treated cells permitted the cloning of several genes whose expression was increased in TGF $\beta 1$ treated cells. ${ }^{7}$ Among them, two structurally related genes were designated $\beta I G-M 1$ and $\beta I G-M 2$. Nucleotide sequencing established that of $\beta \mathrm{IG}-\mathrm{M} 1$ was identical to the previously described cyr61.

Induction of $\beta \mathrm{IG}-\mathrm{M} 1$ in growth arrested cells, as opposed to the induction of CEF10 in cells stimulated to divide, provided the first evidence to suggest that this protein was acting in quite diverse biological processes. ${ }^{7}$

The sequencing of $\beta I G-M 2$ revealed that it was closely related to $\beta \mathrm{IG}-\mathrm{M} 1$ in structure.
The $\beta I G-M 2$ gene was later cloned as ctgf (see below).

GENES THAT WERE IDENTIFIED ON THE BASIS OF THEIR ALTERED EXPRESSION IN TUMOURS Tumour cells are thought to be altered at the level of the regulatory signals controlling normal cell growth. They have provided an unequalled source of biological material in which to study the molecular events leading to uncontrolled and eventually invasive proliferation.

\section{Isolation of nov}

Early studies performed in our laboratory had established that the chicken myeloblastosis associated virus (MAV) induced nephroblastoma constitutes a unique model of Wilms's tumour, a paediatric tumour affecting approximately one in 10000 children. ${ }^{8}$ Histologically, Wilms's tumours and the avian nephroblastomas are very much alike, with varying amounts of heterotypic differentiation occurring, along with the development of kidney tumours. ${ }^{9}$ For this reason, Wilms's tumour is often considered as a "differentiated" tumour. ${ }^{8}$

MAV belongs to a group of tumorigenic replication competent retroviruses that do not carry oncogenic sequences of cellular origin and usually induce tumours by integrating in the vicinity of growth regulatory genes in the host genome. ${ }^{10}$ Cloning of the proviral integration sites of avian and murine retroviruses led to the identification of most of the oncogenes and tumour suppressors that turned out to be major players in the control of cellular growth. This strategy is particularly useful because it does not rely on any particular type of function for the target gene.

Because the genetic basis of Wilms's tumour development is complex and has not been completely elucidated, ${ }^{11}$ the avian tumours provided a unique system in which to identify 
the genes underlying the aberrant differentiation process and the molecular events involved in the initiation and maintenance of the tumour state. Our analysis of MAV integration sites enabled us to establish that in one tumour the MAV proviral genome was integrated into nov, ${ }^{12}$ a gene sharing structural identity with cyr61, cef10, and ctgf. Based on the observation that the amounts of nov transcripts were significantly increased in avian nephroblastomas, we assumed that the alteration of nov was related to tumour development. Whether it was a cause or a consequence still remains to be established.

The discovery of nov had three immediate implications:

(1) The structural relation that had been reported between cyr61 and ctgf was extended to another gene, thereby leading to the concept of a new family of genes ${ }^{1}$ (a family is usually defined as a group of at least three subjects sharing common characteristics).

(2) nov provided the first example of aberrant expression of a CCN gene being associated with tumour development, therefore indicating that the biological properties of this new class of growth regulators extended beyond the normal response to growth stimulation.

(3) The growth inhibitory effect of nov on chicken embryonic fibroblasts (CEFs) also provided the first evidence that the CCN family of genes contains negative regulators and suggested that nov might counterbalance the stimulatory effects of the immediate early CCN proteins.

For many years, these last two features did not receive the attention that they deserved. One possible explanation is that it seemed somewhat paradoxical that a negative regulator of growth should be overexpressed in tumour cells prone to active division and proliferation. In fact, the very nature of the nephroblastoma provides a satisfactory explanation for this apparent contradiction. As stated above, nephroblastomas contain an increased number of developed structures and heterotypic tissues, the differentiation of which also requires negative regulatory factors. It is therefore not so heretical that a gene involved in normal differentiation processes (see below) is aberrantly expressed in highly differentiated tumours.

The inhibition of growth resulting from retroviral driven expression of nov in secondary CEFs was not observed upon infection of $\mathrm{BALB} / \mathrm{c}$ 3T3 mouse cells with retroviral constructs expressing the murine orthologue of nov (P Jolicoeur, 1994, personal communication; EL Suchman et al, 1995, unpublished results), therefore suggesting that the growth inhibitory properties of nov might be effective only in early passage cells, and not in cell lines. Expression of nov was neither detected in quiescent 3T3 mouse cells, nor in human fibroblastic cells (S Kyurkchiev and B Perbal, 1999, unpublished results).

The location of nov on human chromosome $8 \mathrm{q} 24.1$, distal to c-myc, ${ }^{13}$ raised the possibility that some pathologies attributed to c-myc alterations as a consequence of rearrangements in this chromosome region might also involve aberrant expression of nov. Although our search for such cases has not proved successful as yet, this point certainly deserves more attention and should be the matter of a thorough analysis. The recent mapping of WISP-1 to the same region (see below) reinforces the possibility that alterations of CCN genes might play a key role in some pathologies involving chromosome 8q24.1, previously attributed to alterations of c-myc.

Only recently, the aberrant expression of CCN genes in tumours and transformed cells has provided the basis for the identification of three new members of the family. Again, it is not surprising that the various strategies that were used led to the isolation of genes involved at different levels of tumorigenesis and growth control.

\section{Isolation of Elm 1}

In that case, differential display methodology was applied to isolate genes expressed at different levels in low (C23) and high (M2) metastatic K-1735 murine metastatic cells. ${ }^{14}$ It is important to recall that tumour cell populations are heterogenous with regard to their ability to disseminate and give rise to metastases. Low and high metastatic tumour cells that are both part of the tumour cell population are believed to exhibit different biological properties, resulting from the differential expression of genes governing fundamental processes such as adhesiveness, spreading, motility, and proliferation.

Differential screening of RNA species expressed in the low and high metastatic K-1735 variants led to the isolation of Elm1, a gene encoding a 367 amino acid protein, the expression of which was detected in low metastatic but not high metastatic cells. ${ }^{14}$ The acquisition of a metastatic potential is also accompanied by profound modifications of the post transcriptional events that can result in an increased stabilisation or degradation of RNA transcripts. To assess the biological importance of the expression of Elm 1 being associated with a low metastatic potential, the effects of ectopic expression of Elm1 on the tumorigenic potential of high metastatic K-1735 M2 cells were studied. ${ }^{14}$ For this purpose, an Elm 1 expression vector was used to transfect and select G418 resistant K-1735 M2 derived stable transformants expressing different amounts of Elm1 RNA, from no expression up to six times the amount of Elm1 expressed in the C23 low metastatic variant.

The results obtained indicated that the expression of Elm 1 had pronounced effects on the in vivo properties of transfected cells, whereas little effect was seen on the ex vivo growth properties of the transfectants, which only showed a slight increase of doubling time and slight decreased saturation density. ${ }^{14}$

The in vivo effects were much more informative because the expression of Elm1 appeared to affect several parameters. ${ }^{14}$ First, the absolute number of tumours obtained for a given period of time was dramatically reduced 
by the expression of Elm1. Second, as a result of the pronounced inhibitory effect of Elm 1 on the growth properties of transfected cells in vivo, the time needed for tumours to reach a given size was considerably increased. Third, the transfectants that expressed high amounts of Elm 1 gave rise to a much smaller number of lung metastases than those expressing low levels of Elm1.

It therefore appeared that Elm 1 was another example of a CCN protein with a negative type of activity on cell growth. The induction of Elm 1 expression seen three hours after serum stimulation of BALB/c 3T3 cells (fig 2), at a much later time than cyr61 and ctgf, would argue for a role for Elm 1 at a relatively late stage of the G1 phase. ${ }^{14}$

\section{Isolation of $r C O P 1$}

The identification of genes responsible for oncogenic transformation of normal cells has been the subject of many studies over the past 20 years. Despite the considerable amount of information that has emerged from these studies, most of the molecular events that govern progression from the normal to immortalised and transformed stages remain to be uncovered. Thus, the functional bases for the cooperation between the p53 tumour suppressor and activated $\mathrm{H}$-ras oncogene in inducing oncogenic transformation are still obscure.

The differential display strategy that was used to screen mRNAs expressed in normal rat embryo fibroblasts and their counterparts transformed by p53 mutants in cooperation with activated $\mathrm{H}$-ras has allowed the identification of rCOP1, a new gene of the CCN family, encoding a 250 amino acid protein, the expression of which was downregulated in transformed cells. ${ }^{15}$

The expression of $\mathrm{rCOP} 1$ was detected in mouse BALB/c 3T3 cells but was repressed in several transformed derivatives, and retroviral driven ectopic expression of rCOP1 established that rCOP1 expression had a strong negative effect on the growth of rat transformed cells, leading to a cell population showing enrichment in sub-G1 DNA content. Furthermore, rCOP1 overexpression in stably transfected rat cells transformed by p53 and $\mathrm{H}$-ras significantly reduced their tumorigenicity when tested by subcutaneous injection in athymic mice.

These results ${ }^{15}$ identified $\mathrm{rCOP} 1$ as the third member of the CCN family to exhibit properties of a negative regulator of growth.

Interestingly, rCOP1 expression was detected only after repeated passages of rat and mouse embryo fibroblasts and not in primary fibroblasts. ${ }^{15}$ In addition, adult rat tissues did not appear to contain any rCOP1 RNA species, indicating that the expression of rCOP1 was not induced as the result of growth arrest in non-proliferating, fully differentiated tissues.

This is another example of the expression of some CCN genes being susceptible to events leading to the "establishment" of cell lines (see above for nov) and stresses the fact that care should be taken when comparing patterns of
CCN gene expression obtained in embryonic fibroblasts and established cell lines.

\section{Isolation of WISP genes}

The suppressive subtractive hybridisation (SSH) strategy was used to identify targets of the Wnt-1 protein by screening RNAs differentially expressed in C57MG mouse mammary epithelial cells and their transformed counterpart obtained after infection with a wnt-1 expressing retrovirus. ${ }^{16}$ The WNT-1 protein was originally isolated as an insertion site for mouse mammary tumour virus in murine mammary tumour virus (MMTV) induced mammary adenocarcinomas. It is a member of an expanding family of signalling proteins involved in the control of normal cell proliferation and in tumorigenesis.

Two genes (WISP1 and WISP2), ${ }^{16}$ the expression of which was upregulated in wnt-1 transformed cells, were shown to be identical to the previously described Elm1 and rCOP1 genes, respectively. Their expression was not increased by overexpression of wnt- 4 , which does not induce morphological transformation of the C57MG cells, therefore suggesting that WISP expression might play a role in the transformation process. The WISP-1 gene has been mapped to chromosome $8 \mathrm{q} 24.1-8 \mathrm{q} 24.3$ in the vicinity of nov, whereas the WISP-2 gene has been mapped to chromosome 20q12-20q13.1, a region frequently amplified in node negative breast cancers with poor prognosis and in many colon cancers.

The expression patterns and biological properties of WISP1 and WISP2 have both reinforced the idea that the biological properties of CCN proteins might be dependent upon the cellular context and have pointed out the complexity of the regulatory circuitry in which these proteins function.

For example, the upregulation of rCOP1/ WISP-2 in wnt- 1 transformed C57MG epithelial cells ${ }^{16}$ was in apparent contradiction to the downregulation of this gene upon transformation of BALB/c 3T3 fibroblastic cells. ${ }^{15}$ This suggests that the $\mathrm{CCN}$ proteins may have opposing functions in different cell types. Furthermore, in primary human colon adenocarcinomas, the expression of WISP-2 was significantly decreased, and it was not detected in the epithelial tumour cells of mammary carcinoma obtained from wnt- 1 transgenic mice. ${ }^{16}$ In the WISP positive stroma, spindle shaped cells adjacent to capillary vessels stained positive for WISP-2 expression in these tumours.

Similarly, the expression of Elm1/WISP-1, which had been reported to suppress the metastatic potential of murine melanoma cells, ${ }^{14}$ was significantly increased in most human colon carcinomas. ${ }^{16}$ Increased expression of WISP-1 was seen in the stroma of mouse mammary carcinomas produced in wnt-1 transgenic mice (which stained strongly positive for WISP-1 expression), whereas tumour epithelial cells expressed low amounts of WISP- $1 .{ }^{16}$

In apparent contradiction to the tumour suppressor type of activity assigned to Elm $1,{ }^{14}$ overexpression of WISP1 induced accelerated 
growth and morphological transformation of NRK-49F fibroblastic cells. ${ }^{16}$ Furthermore, expression of WISP-1 was found to increase the tumorigenicity of two NRK-49F cell lines established after infection by retrovirus constructs expressing WISP-1. Because these cells would not grow without anchorage, the overexpression of WISP-1 was not sufficient to alleviate the need for proper interactions with the extracellular matrix and attachment. ${ }^{16}$

GENES THAT WERE IDENTIFIED ON THE BASIS OF

THEIR DIFFERENTIAL EXPRESSION IN RSV

TRANSFORMED FIBROBLASTS

Transformation of CEFs by pp60 $0^{\mathrm{v}-\mathrm{src}}$ of Rous sarcoma virus (RSV) is known to alter, either positively or negatively, the transcription of a variety of regulatory and signalling proteins. Because the expression of pp60 $0^{\mathrm{v}-\mathrm{src}}$ had been reported to block the differentiation of myogenic cells, it was proposed that genes whose expression is decreased by pp $60^{\mathrm{v} \text {-src }}$ transformation might act to maintain or induce the differentiated state of target cells.

The strategy used to characterise genes acting in the transduction pathways activated for transformation was usually based on the use of CEFs transformed by a mutant of RSV (tsNY72) expressing a thermosensitive pp60 $0^{\mathrm{v}-\mathrm{src}}$. Upon shifting to the permissive temperature $\left(35^{\circ} \mathrm{C}\right)$, the constitutive tyrosine kinase activity of pp $60^{\mathrm{v}-\mathrm{src}}$ induces the cascade of molecular events that lead to oncogenic transformation.

In the first set of experiments, a cDNA library was prepared from tsNY72 infected cells maintained at the permissive temperature for four to six hours in the presence of $75 \mu \mathrm{M}$ cycloheximide, and screened with a subtracted probe made of labelled cDNA from tsNY72 infected cells grown at $35^{\circ} \mathrm{C}$ hybridised against mRNA from unstimulated cells. Clones obtained with this strategy corresponded to stabilised mRNA whose expression had been induced by $\mathrm{pp} 60^{\mathrm{v}-\mathrm{src}}$. Twelve different immediate early genes were induced, including CEF10, the chicken equivalent of cyr61. ${ }^{17}$

Upon serum stimulation of starved CEFs, the pattern of CEF10 expression was similar to that of cyr61 in murine cells (fig 2). However, no late burst of induction was reported for CEF10. Whether this discrepancy results from variations in the protocols and origin of cells used or represents important differences in the biological properties of murine and chicken genes is not yet clear.

The pattern of CEF10 expression in pp $60^{\mathrm{v}-\mathrm{src}}$ induced cells is interesting. In pp $60^{\mathrm{v}-\mathrm{src}}$ induced cells, CEF10 expression was found to be multiphasic, with two peaks at one and eight hours post shift, a decrease at 12 hours post shift, and a third peak at 24 hours. ${ }^{17}$ Under similar conditions, most immediate early genes were persistently induced for 24 hours. When a mitogenic non-transforming myristoylation defective virus NY315 was used, CEF10 was induced in a linear mode for a period of 24 hours. ${ }^{17}$ These observations indicated that CEF10 production was increased as a result of the $\mathrm{pp} 60^{\mathrm{v}-\mathrm{src}}$ growth stimulatory effect. The cyclic expression of CEF10, which was not observed with NY315, might be related to the transformation process induced by $\mathrm{v}$-src.

In another set of experiments, the differential display strategy was applied to cDNAs prepared from tsNY72 RSV infected CEFs grown at the non-permissive temperature and either shifted to the permissive temperature or maintained at the non-permissive temperature. Screening of the genes differentially expressed in these cells revealed that the expression of the nov gene was downregulated upon the stimulation of CEF growth induced by $\mathrm{pp} 60^{\mathrm{v} \text {-src }}{ }^{18}$

Nuclear run on assays performed on serum starved uninfected CEFs and wild-type pp60 $60^{v-s r c}$ transformed CEFs established that the differential rate of nov transcription in isolated nuclei did not account for the difference in the steady state of nov transcripts measured in quiescent and transformed CEFs. Therefore, the increase levels detected in uninfected cells might result from an accumulation of the nov transcripts as a result of the long half life (eight hours) of the nov transcripts in quiescent cells.

The use of a mutant strain expressing a thermosensitive $\mathrm{pp} 60^{\mathrm{v}-\mathrm{src}}$ revealed that upon shifting to the non-permissive temperature, there was a decline in the numbers of nov transcripts detected in transformed cells between four and eight hours, with a dramatic reduction after 12 hours, and an absence of transcripts after 24 hours. ${ }^{18} \mathrm{~A}$ similar decline in nov expression was seen when CEFs were stimulated to proliferate either after transformation by various oncogenes or after infection with the nontransforming myristoylation defective NY315 mutant. ${ }^{18}$ Therefore, the downregulation of nov expression induced by the stimulation of cell growth and the high concentrations of NOV that were detected in quiescent cells were in striking contrast to the situation observed for other CCN genes, and established that nov was not an immediate early gene (fig 2). The requirement for protein and RNA synthesis in the decrease of nov transcripts upon stimulation of cellular growth indicated that the reduced expression of nov resulted either from the synthesis of a negative regulator of nov transcription or from an increased turnover of nov transcripts. ${ }^{18}$

Our observation that the expression of nov was modulated during the progression of the cell cycle and reached a peak at the G2 phase (S Middendorp and B Perbal, 1995, unpublished results) suggests that the increased synthesis and accumulation of stable nov transcripts at that late stage might be required for proper differentiation.

GENES THAT WERE ISOLATED ON THE BASIS OF AN IMMUNOLOGICAL CROSSREACTIVITY OR A STRUCTURAL IDENTITY WITH CCN GENES Polyclonal antibodies raised against platelet derived growth factor (PDGF) were used to characterise and isolate the protein(s) responsible for the PDGF related mioattractant activity that was detected in conditioned medium from human umbilical vein endothelial cells (HUVEC).$^{19}$ This approach has led to the identification of an anti-PDGF crossreacting protein 
with a reported apparent molecular mass of $38 \mathrm{kDa}$. This protein, which was shown to possess the major chemotactic and mitogenic activity previously attributed to PDGF, was designated CTGF (connective tissue growth factor).${ }^{19}$ Cloning of CTGF revealed that it was the human orthologue of fisp 12 and $\beta I G-M 2$ (see above). As expected from its structural identity with fisp 12 , the ctgf gene was shown to be rapidly induced by serum in human skin fibroblasts (fig 2), independently of protein synthesis, therefore confirming that it was indeed an immediate early gene. ${ }^{20}$

In agreement with previous studies that led to the discovery of $\beta \mathrm{IG}-\mathrm{M} 2$, the ctgf gene, which is expressed in unstimulated fibroblasts, ${ }^{21}{ }^{22}$ was reported to be induced by TGF $\beta$ in the absence of protein synthesis. ${ }^{70} 23$ From these observations, a potential role for CTGF in fibrotic diseases has progressively emerged, and it is now well established that ctgf mRNA and protein are overexpressed in fibrotic lesions of several major organs in humans, including liver, kidney, gingiva, cardiovascular system, pancreas, bowel, and eye (reviewed by Brigstock $^{3}$ and Essam and colleagues ${ }^{4}$ ). However, the relation between TGF $\beta$ and ctgf is not obligatory because several studies have shown that the activation of ctgf expression can proceed independently of TGF $\beta$ (reviewed by Essam and colleagues ${ }^{4}$ ).

Because of its identification as a downstream target of TGF $\beta$, ctgf has been studied extensively over the past few years and our growing knowledge indicates that, as reported for other CCN genes, its biological properties and regulation of expression are dependent upon the cellular context and the nature of the cells in which it is produced and/or acting. Initially reported to induce cell proliferation, survival, and extracellular matrix production, CTGF has also been shown to be apoptotic in human aortic smooth muscle cells and human breast cancer MCF-7 cells. ${ }^{24-26}$

Another experimental approach, based on the screening of expressed sequence tag (EST) databases, with the WISP-1 protein sequence, ${ }^{16}$ allowed the identification of WISP-3, a gene encoding a 354 amino acid new member of the CCN family with slightly different structural features to the other members: it is the only member thus far that does not show the characteristic conservation of cysteines.

Until recently, very little information was available about the biological properties of WISP-3. The WISP-3 gene has been reported to be significantly overexpressed in human colon carcinoma, ${ }^{16}$ and putative loss of function mutations in the WISP-3 gene have been associated with progressive pseudorheumatoid dysplasia in humans, an autosomal recessive form of spondyloepiphyseal dysplasia. ${ }^{27}$

On the one hand, the different systems in which the CCN genes have been identified made it obvious that their expression ought to be involved in a wide variety of biological processes in normal and pathological conditions. However, on the other hand, the striking conservation of their modular organisation with 38 cysteins, the position and number of which have been conserved throughout the family members and during evolution, suggested that they might share some kind of functionality.

Until now, most of the studies performed with the various $\mathrm{CCN}$ genes and proteins have been descriptive and have been performed on different biological systems. Unfortunately, only in a very few instances, were studies performed in parallel to compare the expression or the activity of different members of the family. This type of approach might turn out to be very fruitful in the case of CCN proteins for which no biological assay is available as yet. Obtaining this type of information through collaborative efforts would undoubtedly lead to an integrated view of CCN gene expression and functions at a very reduced cost.

The use of different systems has increased the number of results that appear to be "conflicting" if one does not take into account the variety of physiological conditions considered. There is no doubt that if the CCN proteins play, as one can guess, key roles in so many different fundamental regulatory processes, the major issue is understanding the structural basis for their biological functions. This goal will be reached by the combination of different techniques, including purification of biologically active CCN proteins, identification of their targets and cofactors, directed mutagenesis of crucial amino acids, the construction of chimaeras, and the manipulation of genes in the context of living animals.

Before this goal can be achieved, there are issues that remain unresolved and need to be considered for each member in the context of the CCN family as a whole.

Based on the results that we have obtained with nov I will consider below: (1) the relation between the structure and subcellular localisation of CCN proteins, (2) the mechanisms governing the temporal and spatial regulation of CCN gene expression, (3) the implication of the CCN proteins in pathological conditions, and (4) the identification of proteins and ligands that interact with $\mathrm{CCN}$ proteins.

\section{Structure and subcellular localisation of CCN proteins}

Figure 3 shows the modular structure of the $\mathrm{CCN}$ proteins. Although they have a very conserved multimodular organisation, with four modules sharing identity with insulin-like growth factor binding proteins (IGFBPs), Von Willebrand factor, thrombospondin, and a cystein knot containing family of growth regulators, the CCN proteins have distinctive biological properties and are differentially regulated.

Because of their partial identity with IGFBPs and the low affinity binding of IGF-I and IGF-II to CTGF, ${ }^{28}$ a few groups in the IGF field have attempted to rename the CCN proteins using an IGFBP related system. Although it is quite possible that both IGFBPs and CCN proteins participate in common regulatory pathways, there is as yet no functional evidence to support such a renaming. ${ }^{29}$ From discussions at the first international workshop on the 
Table 1 Proposed nomenclature for $C C N$ proteins

\begin{tabular}{lll}
\hline CCN nomenclature & Current names & Alternative designations \\
\hline CCN 1 & CYR61/CCE10 & IGFBP-rP 4 \\
CCN 2 & CTGF/FISP12 & IGFBP-rP 2, Hcs 24 \\
CCN 3 & NOV & \\
CCN 4 & WISP-1/ELM 1 & \\
CCN 5 & WISP-2/rCOP-1 & \\
CCN 6 & WISP-3 &
\end{tabular}

CCN names were given according to their chronological identification. It is suggested that a lower case letter should be used to indicate species when needed (for example, hCCN1 for human cyr61).

CCN family of genes, a unifying nomenclature is now proposed for the CCN genes and proteins (table 1). It is also suggested that the nomenclature committee of the CCN society (ccnsociety@mageos.com) should be contacted for the attribution of names for new CCN members.

The multimodular organisation of the CCN proteins raises interesting questions as to the participation of each module in the function of the full length protein. Either the activities of each module add up or they confer on the whole protein specific functions that might substitute or add to the function of the individual modules. Such a modular structure also suggests that the different modules correspond to functional domains that can interact either sequentially or simultaneously with other partners, and that the final biological properties of the CCN proteins might be dependent upon different combinatorial effects.

Studies performed with NOV, CTGF, and WISP-2 have provided valuable information about the structural basis for some biological properties of the CCN proteins.

The nov gene was discovered as an integration site for the MAV retrovirus in avian nephroblastomas (see above). ${ }^{12}$ This gene was designated nov because it was highly expressed in all nephroblastomas compared with adult kidney, where its expression was low but still detectable. ${ }^{9}$ In one sample (tumour 725 ), the integration of MAV into the second intron of nov resulted in the U5 long terminal repeat (LTR) driven expression of a chimaeric nov mRNA containing 91 3'-proximal viral nucleotides and $2.0 \mathrm{~kb}$ of cellular sequences. As a consequence, the first putative initiation codon corresponded to an internal methionine codon in the full length NOV protein, and the resulting chimaeric protein, composed of 253 amino acids, was expected not to be secreted because it was deprived of the signal peptide

\begin{tabular}{|c|c|c|c|c|c|}
\hline & $\% \mathrm{ID} / \mathrm{HO}$ & IGFBP & VWC & TSP1 & CT \\
\hline CTGF & $100 / 100 \bigcirc$ & & & & \\
\hline CYR61 & $44 / 600$ & & & & \\
\hline NOV & $48 / 640$ & & & & \\
\hline ELM1/WISP1 & $41 / 570$ & & & & \\
\hline COPI/WISP2 & $32 / 410$ & & & & \\
\hline WISP3 & $36 / 520$ & & & & \\
\hline
\end{tabular}

Figure 3 Multimodular structure of the CCN proteins. CT, cystein knot containing family of growth regulators-like domain; IGFBP, insulin-like growth factor binding protein-like domain; TSP1, thrombospondin-like domain; and VWC, Von Willebrand factor-like domain. identified at the N-terminus of NOV and all other CCN proteins. Although increased expression of nov was detected in all nephroblastomas tested (including those induced by the MAV2-O strain, which also induces osteopetrosis), none of them was found to contain a physically altered nov gene (CL Li et al, 2000, unpublished results). ${ }^{12}$

The construction of retroviral competent ovian recombinants, expressing either the full length nov RNA or the truncated version of nov expressed in tumour 725 , allowed us to establish that the ectopic overexpression of the full length nov in actively growing CEFs (which did not express endogenous nov) inhibited their growth. ${ }^{12}$ Recombinant viruses replicated in these cells (as shown by RNA expression) and gave rise to viral stocks; the growth inhibitory effect of nov did not induce cell death but rather blocked the cells in the cell cycle, probably at the G2-M transition. On the contrary, the expression of the truncated nov RNA species did not interfere with the growth of the CEFs and induced their morphological transformation. ${ }^{12}$ From these results it was concluded that nov was a protooncogene with antiproliferative activity. Therefore, it could be concluded that the development of nephroblastomas in chickens was associated with an increased expression of either a full length or a truncated NOV protein.

Because the fates of truncated and full length NOV proteins are expected to be quite different (fig 4), these results suggested that the biological properties of the NOV proteins might depend upon their structure and their subcellular localisation.

The immunofluorescence detection of a NOV related protein in the nucleus of several different cell lines and frozen tissue preparations raised the intriguing possibility that it might be involved more directly in the regulation of gene expression. Because the amount of nuclear NOV protein was found to vary greatly (from zero to high concentrations) among various cell lines (B Perbal, 1997, unpublished observations and PN Schofield, 1998, personal communication), the nuclear localisation of NOV might be related to their proliferation and cell cycle status.

Several lines of evidence confirmed the existence of a nuclear NOV related protein and

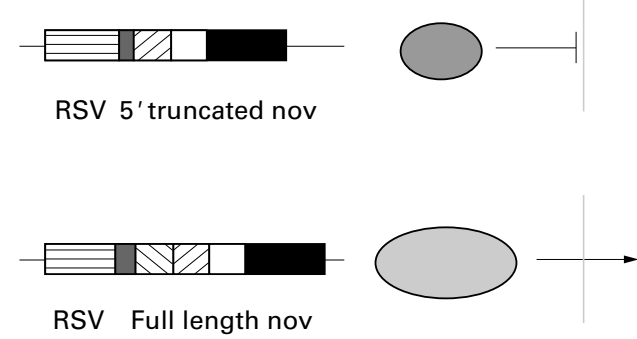

Figure 4 Fate of the full length and truncated proteins. Rous sarcoma virus (RSV) driven expression of the

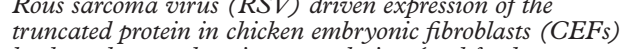
leads to the cytoplasmic accumulation (and further processing?) of the truncated NOV protein, whereas the presence of the signal peptide in full length NOV governs its secretion. 
suggested that it was indeed involved in the regulation of transcription.

AN AMINO TRUNCATED NOV RELATED PROTEIN IS LOCALISED IN THE NUCLEUS OF HeLa AND 143 CELLS

A $31 / 32 \mathrm{kDa}$ doublet of NOV protein was identified by western blotting in the nuclear fraction of human epitheloid carcinoma HeLa cells, and human osteosarcoma 143 cells. $^{30}$ Because the antibodies used in this study were directed against the C-terminus of $\mathrm{NOV}$, the $31 / 32 \mathrm{kDa} N O V$ isoform was thought to be an amino truncated form of $\mathrm{NOV}$.

The nuclear detection of $\mathrm{NOV}$ was reminiscent of a situation reported previously for several other secretory proteins. In the absence of a conventional nuclear localisation signal (NLS) in NOV, its nuclearisation might be governed by the KKGKKCLRTKKS motif, which is similar to the basic motif involved in the nuclear localisation of fibroblast growth factor 3 (FGF3).

Although the biological importance of NOV nuclear targeting remains unclear, our expectation is that the $31 / 32 \mathrm{kDa} N O V$ isoform might modulate gene expression during normal development. The biochemical identification of this nuclear NOV related protein is under way.

THE NUCLEAR 31/32 kDa NOV RELATED PROTEIN COLOCALISES WITH THE TRANSCRIPTIONAL MACHINERY IN THE 143 CELLS

As a first step in establishing the localisation of the nov protein in the nucleus of these cells, we took advantage of the fact that herpes simplex virus 1 (HSV-1) encoded infected cell proteins 4 and 8 (ICP4 and ICP8) can be used as physical markers for the transcription and replication machineries, respectively. The ICP4 protein is a transcriptional transactivator localised in the nucleus of HSV infected cells, where it is responsible for the regulation of HSV gene expression, whereas ICP8 is a single stranded DNA binding protein that is found in the nuclear compartment, where viral DNA synthesis takes place. ${ }^{31}$

To determine whether NOV protein could be detected in the nucleus of actively growing cells, three series of experiments were performed. In the first, uninfected fixed 143 cells were exposed to the anti-nov K19 rabbit antibody and then to biotinylated goat antirabbit immunoglobulin, followed by avidin bound to Texas red. In parallel experiments, cells were treated with the anti-nov K19 antibody and incubated directly with goat antirabbit Texas red conjugated antibodies. Nuclei from uninfected 143 (fig 5A) cells showed a strong positive response to the K19 anti-nov antibody. In uninfected actively growing cells, the nuclear NOV protein appeared to be localised in the nucleoplasm and in nucleoli. Positive staining was also seen at the periphery of the nucleus (probably in the Golgi) and in the cytoplasm of these cells.

In the second series of experiments, cells were infected with $\mathrm{HSV}-1$ before incubation with rabbit anti-nov (K19), mouse anti-ICP4, and mouse anti-ICP8 antibodies. It has been reported previously that early after HSV infection, ICP4 is diffusely distributed throughout the infected cell nucleus and that, after the onset of viral DNA replication, staining for ICP4 was associated with discrete dense bodies. In contrast, ICP8 labelling was fairly constant throughout infection, giving rise to a granular pattern that filled the infected nucleus.

Infected 143 cells were first incubated simultaneously with either both the rabbit anti-K19 and the mouse anti-ICP4 antibodies and then with goat antimouse fluorescein isothiocyanate (FITC) conjugated antibodies (reacting with anti-ICP4 and anti-ICP8) or with biotinylated goat antirabbit immunoglobulin before incubation in the presence of Texas red conjugated avidin (allowing indirect visualisation of the K19 antibody).

As shown in fig 5B, ICP4 (green fluorescence) and NOV (red fluorescence) overlapped in the nucleus of infected 143 cells, whereas ICP8 (green fluorescence) and NOV (red fluorescence) did not colocalise (fig 5C). As expected, the nucleoli did not contain dual staining. These experiments suggested that the major fraction of the nuclear NOV isoform was localised in the compartment where transcription occurs and was not associated with the
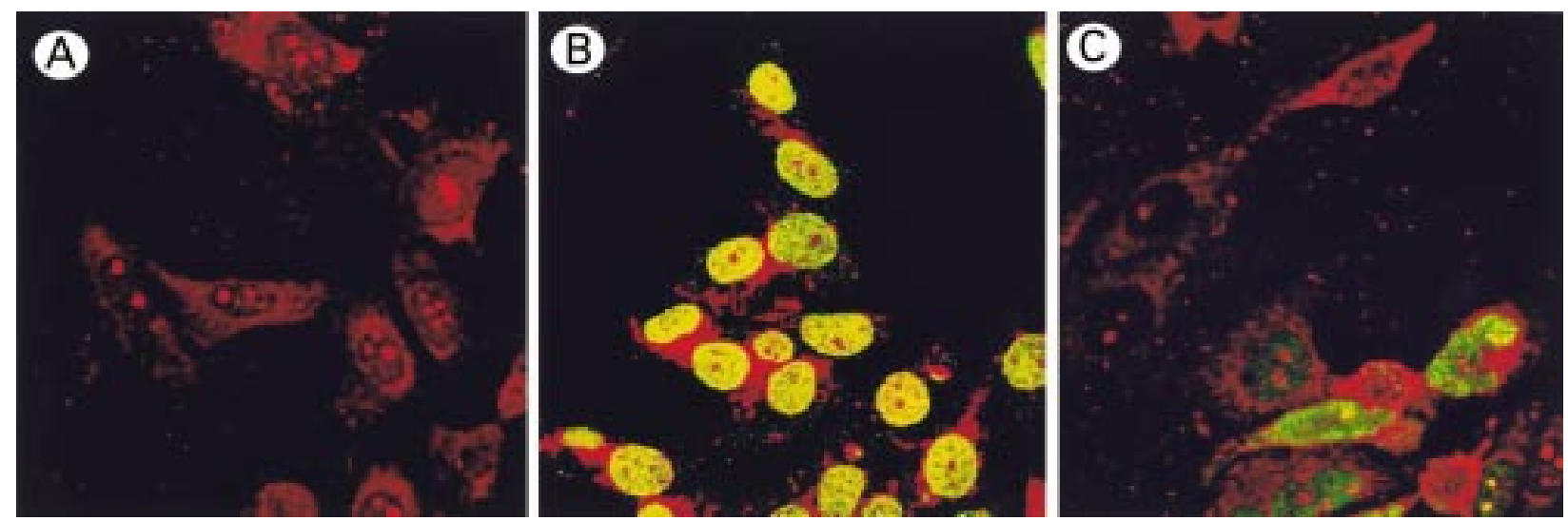

Figure 5 Confocal immunocytolocalisation of NOV in the nucleus of 143 osteosarcoma cells. (A) staining with anti-nov antibodies, (B) double staining with anti-nov and anti-HSV-ICP4 (herpes simplex virus infected cell protein 4) antibodies, (C) double staining with anti-nov and HSV-ICP8 antibodies. The yellow colour indicates colocalisation of ICP4 and NOV. 
replication machinery (B Perbal, 1997, unpublished data).

THE NOV PROTEIN INTERACTS WITH THE RPB7 SUBUNIT OF RNA POLYMERASE IN A YEAST TWO HYBRID SYSTEM

A yeast two hybrid screening system was used to isolate cDNAs encoding proteins able to interact with the human NOV protein. ${ }^{30} \mathrm{~A}$ DNA fragment encoding NOV codons 29 to 357 was amplified by the polymerase chain reaction (PCR) and inserted into pGBT9 (Clontech, Palo Alto, California, USA) in frame with the DNA binding domain of Gal4. The resulting plasmid (pNOV) was used as "bait" to screen three cDNA libraries (an Epstein-Barr virus transformed human peripheral blood lymphocyte library (gift from Aviron Inc.), a HeLa cell library, and a normal human brain library from Clontech, all provided by Dr B Roizman, Kovler Laboratory, University of Chicago, USA), which were fused to the Gal4 transcriptional activation domain in pACT.

Establishing the 3'-proximal sequence of the inserts at the 5' boundary of the Gal4 DNA domain fusion (B Perbal, 1997, unpublished results; $\mathrm{CP} \mathrm{Li}$ et al, 2000, unpublished results $)^{30}$ allowed us to identify several independent clones with sequences that match completely with the published sequence of the rpb7 subunit of human RNA polymerase II. Because it has been established that the rpb7 subunit alone does not give rise to false positives under the conditions used ( $M$ Verner, 1998, personal communication), our results strongly suggested that the nuclear amino truncated NOV related protein is involved in the regulation of transcription through its interaction with the RNA polymerase holoenzyme.

A NOV RELATED PROTEIN CAN BE DETECTED AT THE NUCLEAR ENVELOPE

We have shown that the NCI-H295R cells that have been established from an invasive adrenocortical carcinoma secrete increased concentrations of NOV protein (S Kyurkchiev et al, Proceedings of the first international workshop on the CCN family of genes, 17-19 October 2000, Saint-Malo, France). When the immunogold procedure was used to perform an immunocytochemical localisation of the NOV protein in these cells, we found that the cytoplasm, the plasma membrane, and the nuclear envelope stained positive. Unexpectedly, the distribution of the positive grains in the cytoplasm of the NCI-H295R cells and the absence of any recognisable secretory granule or secretory vesicle suggested that shuttling of the NOV protein in these cells did not follow the conventional pathway (G Thomopoulos et al, 2001, in press). The mode of secretion of the protein is currently under investigation.

The detection of an immunoreactive NOV related protein at the nuclear pores of NCIH295R cells was another piece of evidence suggesting that NOV might be targeted to the cell nucleus.
A NOV RELATED PROTEIN BINDS THE PROMOTER OF HUMAN PLASMINOGEN ACTIVATOR INHIBITOR TYPE 2

In recent studies performed to identify the factors responsible for the transcriptional regulation of the human plasminogen activator inhibitor type 2 (PAI-2) gene, competition electrophoretic mobility shift assays identified two cDNAs from a HeLa cell library encoding partial peptides that specifically bound to the transcriptional regulatory motif (TRM), previously found to be essential for constitutive PAI-2 transcription. Sequencing of the cDNAs established that one of these peptides was identical to the fifth domain of $\mathrm{NOV}^{32}$ therefore reinforcing the possibility that a NOV related protein might indeed be involved in transcriptional regulation.

Because there is no evidence as yet for alternative splicing of the nov RNA, the detection of a NOV related protein in the nucleus and in the cytoplasm of the cells raises fundamental questions as to the biochemical constitution of these proteins and their association. To investigate these questions, we have now constructed different types of vectors expressing tagged full length and truncated NOV proteins. Studies aimed at characterising processes governing the turnover and subcellular localisation of the different NOV related proteins and their functional relation have been undertaken.

In the absence of compelling evidence for the expression of new members of the CCN family exhibiting a nuclear localisation, it is tempting to relate these various observations to the detection of an amino truncated NOV isoform in the conditioned medium of nov expressing cells.

The analysis of conditioned medium from SF9 insect cells infected with a nov expressing recombinant baculovirus identified a $25 \mathrm{kDa}$ NOV protein as an amino truncated isoform. $\mathrm{N}$-terminal sequencing performed on the purified secreted protein revealed that the truncated protein was made of the two C-proximal domains of $\mathrm{NOV}$, with an $\mathrm{N}$-terminal sequence (AYRPE), suggesting that it was the result of a proteolytic cleavage of the full length secreted NOV protein. ${ }^{33}$ The existence of a truncated form of CTGF with a similar N-terminal sequence $^{34}$ suggests that specific proteolysis of these CCN proteins might be a key element in the regulation of their biological activity.

A truncated NOV protein with an apparent molecular mass of 30-32 kDa can be detected in the conditioned medium of naturally expressing cells such as NCI-H295R (G Thomopoulos et al, 2001, in press); transfected Madin Darby canine kidney (MDCK) cells ${ }^{35}$; transfected human glioblastomas (B Perbal, 2000, unpublished results); in five day old human myoblasts, but not in myotubes ( Kyurkchiev and B Perbal, 1999, unpublished results); and in different human biological fluids, such as urine, amniotic fluid, ${ }^{36}$ and cerebrospinal fluid. ${ }^{36}$ Our working hypothesis is based on the assumption that the elimination of the N-proximal modules confer on the truncated NOV protein growth stimulatory properties, as opposed to the inhibitory properties of 


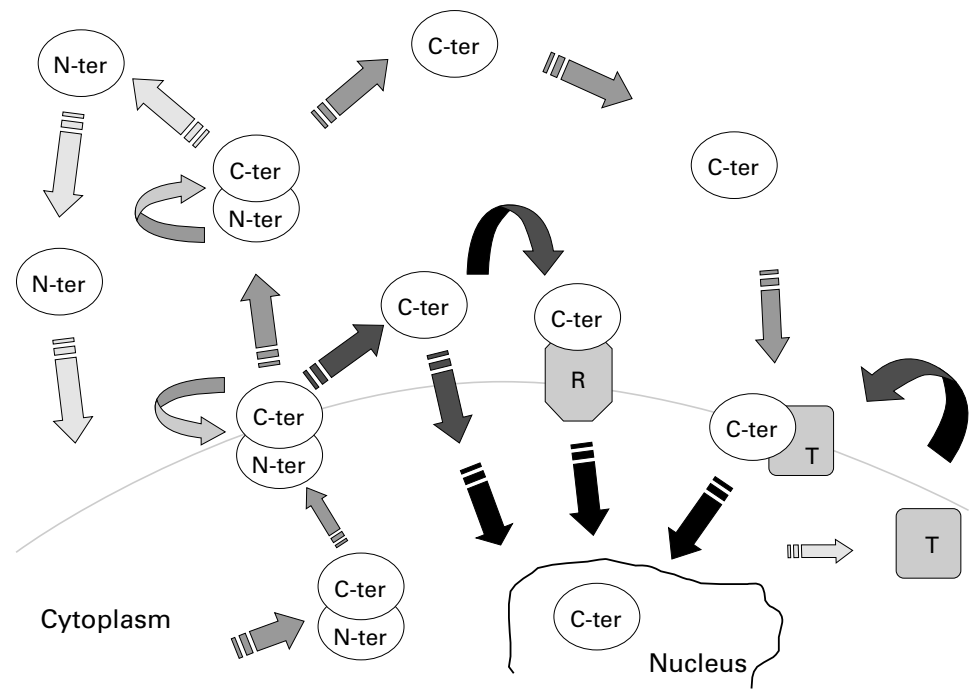

Figure 6 Schematic hypothetical pathways leading to the potential internalisation of the amino truncated NOV protein. In all cases, the secretion of a full length NOV protein is thought to be required for further processing. The full length NOV protein might be secreted and processed at the membrane site, the $C$-proximal moiety of the protein being internalised directly or indirectly through specific interactions with either a receptor or a transporter. Alternatively, the NOV protein could be released into the medium or the extracellular matrix where it would be submitted to proteolysis. The amino part of the protein might itself play an important role in signalling, either directly or indirectly. $C$-ter, amino truncated protein; $N$-ter, $N$-proximal moiety of the protein; $R$, receptor; $T$, transporter.

the full length NOV protein (see above). The oncogenic properties of the truncated NOV protein expressed in avian nephroblastoma (see above), and the growth inhibitory properties of rCOP $1,{ }^{15}$ might therefore result from the disruption of the regulatory balance existing in the full length protein, between a negative $\mathrm{N}$-proximal domain and a positive C-terminal domain. In the case of an amino truncated NOV protein, constitutive positive properties would result from the lack of negative regulation conferred by the first module, whereas in the case of $\mathrm{rCOP} 1$, the lack of positive effects would result from the lost of the C-terminal module.

Indirect evidence suggesting that the C-terminus of NOV is not freely accessible in the native protein came from studies aimed at setting up an enzyme linked immunosorbent assay (ELISA) to measure the concentrations of NOV in biological fluids (S Kyurkchiev et al, Proceedings of the first international workshop on the CCN family of genes, 17-19 October 2000, Saint-Malo, France). By performing ELISA with phosphate buffered saline (PBS) or Triton treated NCI-H295R cells we established that the NOV protein was present at the cell membrane and that a considerable amount of NOV could be found in the cytoplasm of these cells. This conclusion was confirmed by indirect immunofluorescence assays, which indicated that the NOV protein was widely distributed in the cytoplasm of the NCI-H295R cells, sometimes associated with perinuclear granules, suggesting labelling of the Golgi. Unexpectedly, the NOV protein was not detected when absorption ELISA was performed with conditioned medium from NCIH295R cells in which the presence of secreted NOV had been checked for by western blotting. This suggests that in the native NOV protein, the C-terminus of NOV was not accessible to the antibodies, either because of conformational constraints or because it was combined with other partners.

The possibility that physical interactions between the C-proximal and $\mathrm{N}$-proximal domains of NOV can regulate the activity of the native protein is under current investigation.

Thus, the balanced production of truncated and full length NOV isoforms might be tightly regulated and be dependent upon physiological conditions. This aspect might be particularly important in the case of cancer cells, which overproduce many different kinds of proteases. The disregulation of proteolysis would increase the relative ratio of truncated over full length isoforms, therefore leading to abnormal signalling. However, the situation is probably not that simple. In the course of the studies that we have initiated to identify the molecular events leading to the secretion of NOV isoforms, we have established that the concentration of truncated NOV protein in the conditioned medium of eukaryotic cells is not related directly to the amount of the released full length $48 \mathrm{kDa}$ protein (V Martinez and B Perbal, 2000, unpublished results), therefore suggesting that the production of the amino truncated NOV isoform is not the sole result of NOV post translational processing.

The possibility that the detection of a nuclear NOV protein did not result from the intracellular addressing of NOV, but was related to the secretion of a full length NOV, was suggested by experiments in which inhibition of the secretion of the full length NOV did not increase the concentration of nuclear NOV in the treated cells (B Perbal, 1997, unpublished observations). It is tempting to speculate that the truncated NOV protein is targeted to the nucleus after post translational proteolysis of the secreted NOV protein, either at the surface of the cell or in the matrix by one of the mechanisms depicted in fig 6 .

The isolation of several biologically active truncated forms of CTGF in biological flu$\operatorname{ids}^{334}$ is another example that highlights the potential importance of post translational modifications of CCN proteins, and stresses the need for tight control to ensure balanced production of the various isoforms if processing and biological activity are related. In that case, the levels of low mass stable CTGF isoforms were proposed to be qualitatively and quantitatively dependent upon several factors, such as tissue of origin, species, or stage of the cell cycle. ${ }^{3}$ Again, the amino truncated $10 \mathrm{kDa}$ CTGF, which contains only the C-terminal module of CCN proteins, exhibited mitogenic properties, confirming that the $\mathrm{N}$-proximal modules are not required for the positive regulation of growth. ${ }^{3}$ However, the complexity of the structure-activity relation is exemplified by the fact that the $10 \mathrm{kDa}$ CTGF molecule is mitogenic for BALB/c 3T3 cells, vascular smooth muscle cells, and endometrial stromal cells but not endothelial cells. ${ }^{3}$

The study of the mechanisms governing the production of the truncated CCN proteins 
should result in a better insight into the biochemical properties of the four constitutive modules and their functional interactions.

\section{Regulation of CCN RNA and protein expression}

Another fundamental question regarding the biological properties of the CCN proteins concerns the way their expression is regulated both in space and time. Because a large quantity of information concerning the patterns of cyr6 1 and ctgf expression has been published in recent reviews, ${ }^{2-4} \mathrm{I}$ will focus on results obtained with nov and will attempt to highlight the specificities of each system.

PROMOTER SEQUENCES AND GENE EXPRESSION As stated above, the expression of the cyr61 and ctgf genes is induced early upon stimulation of fibroblast proliferation, whereas Elm1 and $\mathrm{rCOP}-1$ exhibit delayed kinetics of induction and the expression of nov is downregulated under similar conditions (fig 2). This differential expression pattern and the variety of effectors involved in the activation or repression of CCN genes have suggested that distinct regulatory elements govern their expression. Indeed, the comparison of ctgf, cyr61, and nov promoter sequences did not show any obvious conservation. $^{3}$ 37-39

The induction of cyr61 by serum and PDGF in fibroblasts was reported to be dependent upon a serum responsive element (SRE)-like motif at position $-1912 /-1933$ in the $2 \mathrm{~kb}$ 5'-proximal promoter sequences, which are sufficient to confer serum inducibility. ${ }^{37}$ The expression of ctgf was also found to be stimulated by PDGF and epidermal growth factor (EGF) in human fibroblasts. ${ }^{23}$ Similarly, both cyr61 and ctgf were reported to be induced by fibroblast growth factor (FGF)..$^{523}$ The expression of cyr61 is also induced by vitamin D3 in human fetal osteoblasts ${ }^{40}$ by oestrogen and tamoxifen in uterine cells of ovariectomised rats, ${ }^{41}$ and hippocampal immortalised cells undergoing neuronal differentiation. ${ }^{42}$

The rapid induction of cyr61 (peak after 20 minutes, decreased at 60 minutes, and absent at two hours) by $100 \mathrm{ng} / \mathrm{ml} \quad 12-\mathrm{O}-$ tetradecanoylphorbol-13-acetate (TPA) ${ }^{5}$ was in pronounced contrast to the expression of CEF10 (the avian homologue of cyr61), which was reported to be repressed to $<20 \%$ of the basal value at 60 minutes, and gradually increased to about 10 times the basal value at 24 hours. ${ }^{17}$ Based on the time course for the translocation-activation-deactivation of protein kinase $\mathrm{C}$ (PKC), the expression pattern of CEF10 in the presence of $100 \mathrm{ng} / \mathrm{ml}$ TPA suggested that the expression of CEF10 is repressed at one hour, when PKC is transiently activated, and derepressed when PKC is degraded. ${ }^{17}$ Similarly, stimulation of serum starved cells by $50 \mathrm{ng} / \mathrm{ml}$ TPA for six hours resulted in the complete downregulation of nov in CEFs. ${ }^{18}$ The downregulation of nov expression induced by serum and by TPA could be abolished by treatment with the $\mathrm{H} 7$ inhibitor of $\mathrm{PKC}$, suggesting that $\mathrm{PKC}$ might play a role in the decrease in the half life of nov RNA transcripts. ${ }^{18}$ The sequences involved in the delayed downregulation of cyr61 and ctgf expression have not been identified as yet.

Although the expression of CEF10/3IG-M1 (the mouse equivalent of cyr61) and $\beta \mathrm{IG}-\mathrm{M} 2$ (the mouse equivalent of ctgf) were reported to be inducible by TGF $\beta$ in AKR-2B mouse embryo fibroblasts, ${ }^{7}$ the expression of cyr61 was not found to be significantly induced by TGF $\beta$ in human skin fibroblasts or NIH3T3 cells. ${ }^{38}$

These "conflicting" results indicated that the regulation of CCN gene expression may vary in different species (cef10 and cyr61), and depend upon the type of cells used in the same species (AKR-2B versus NIH3T3). These observations stressed once more the fact that one must be extremely cautious in comparing results obtained with different systems.

Given the importance of TGF $\beta$ signalling in several fundamental biological processes, much attention has been paid to the relation between TGF $\beta$ and ctgf expression. Promoter analysis of ctgf and methylation interference assays have led to the identification of a 13 nucleotide TGF $\beta$ putative responsive element (TbRE), which is conserved in the promoter of ctgf throughout species and appears to be specific for TGF $\beta$ induced transcriptional activation of ctgf..$^{38}$ Whether binding of a specific factor to this sequence is responsible for the prolonged induction of ctgf mRNA after short term exposure to TGF $\beta$ remains to be established.

The expression of nov was not affected by TGF $\beta$ in either NRK-49 F (D Lawrence and B Perbal, 1995, unpublished observations) or NIH3T3 and human skin fibroblasts. ${ }^{38}$

Ex vivo experiments performed with the human nov promoter indicated that sequences localised between positions -405 and -62 had a negative effect on transcriptional activity when measured by chloramphenicol acetyl transferase (CAT) assays. ${ }^{11}$ A comparison of the promoter sequences from xenopus, chicken, and human nov did not reveal any significant conservation (fig 7). A stretch of 19 nucleotides (GCAGGCCCCGGCGCGC CGC) appeared to be conserved in the human and chicken nov promoter. Whether this nov conserved element (NCE) binds a regulatory factor involved in the negative regulation of nov promoter activity is under investigation. The activity of the human nov promoter was downregulated indirectly by the WT1 protein. ${ }^{39}$ It is worth noting that the ctgf promoter was also recently reported to be a target for WT1 transcriptional regulation. ${ }^{43}$ Screening of oligonucleotide arrays and northern blotting established that ctgf expression was upregulated in a Wilms's tumour cell line (WiT49A) transfected by a dominant negative mutant of WT1, whereas ctgf promoter activity was repressed by wild-type WT1 protein. As established in the case of nov, the downregulation of ctgf promoter activity was not mediated by canonical WT1 recognition elements. ${ }^{43}$ These results reinforced the possibility that the alteration of 
A

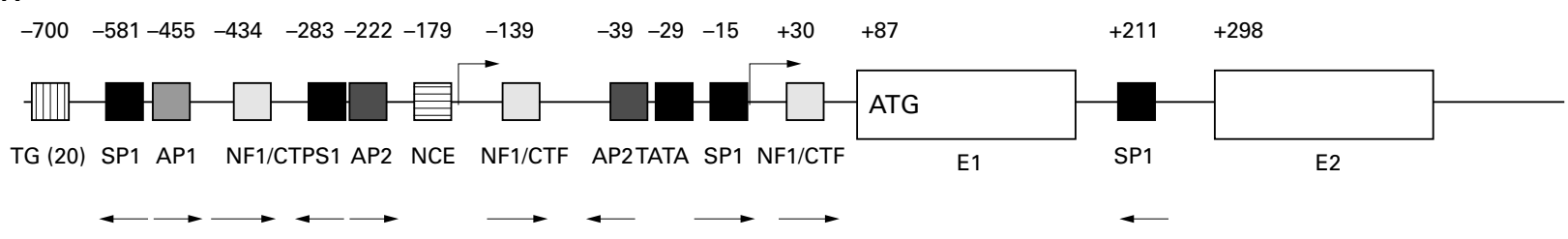

B

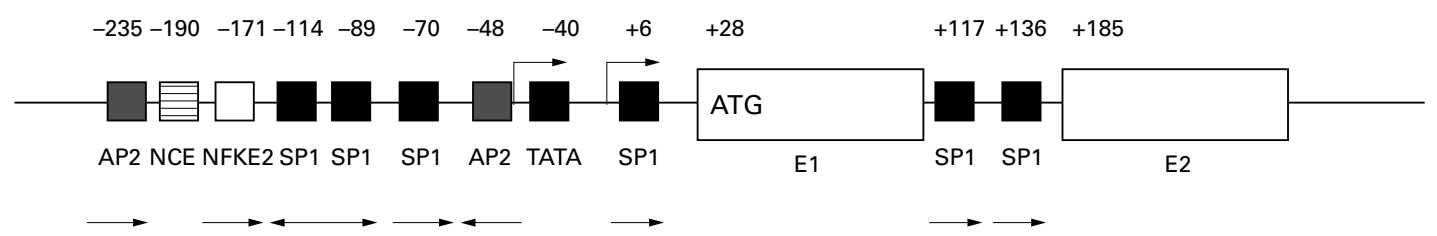

Figure 7 Schematic structure of the human (A) and chicken (B) nov promoters. The putative binding sites were identified on the basis of their consensus nucleotide sequences.

nov expression observed in avian nephroblastomas was indeed related to impaired kidney blastema differentiation and tumour development.

EXPRESSION PATTERN IN NORMAL EMBRYONIC AND ADULT TISSUES

Early studies indicated that the CCN genes were differentially expressed in normal tissues during development.

Northern blot analysis of chicken embryonic and adult total RNA established that the expression of the nov gene was regulated both temporally and spatially during development, ${ }^{9}{ }^{12}$ with nov RNA detected either only at the embryonic stage (heart) and adult stage (lung), or at both stages (brain). Muscle and intestine were also found to express nov at the embryonic stage, whereas adult spleen was positive for nov expression. Embryonic kidneys expressed high amounts of nov, whereas much lower amounts were detected in the kidneys of birds after hatching. ${ }^{9}$ In human tissue samples, abundant amounts of polyA nov RNA were detected by northern blotting in heart, brain, prostate, testes, and pancreas, whereas low amounts were detected in spleen, ovary, small intestine, colon, peripheral blood leucocytes, lung, skeletal muscle, and kidney. ${ }^{36}$ RNase protection assays performed on total RNA of 8 and 10 week old embryonic human tissues indicated that nov was highly expressed in the adrenal gland and to a lesser extent in kidney, limb bud, and spinal cord, whereas heart, liver, intestine, lung, placenta, and testis were found to be negative for nov expression (S Kocialkowsky et al, 2001, in press).

A cDNA-PCR analysis of WISP RNA expressed in adult and fetal human tissues ${ }^{16}$ established that WISP-2 RNAs were to be found in a rather restricted panel of tissues, including adult skeletal muscle, colon, ovary, and fetal lung, whereas WISP-1 RNAs were detected in adult heart, kidney, lung, pancreas, ovary, spleen, and small intestine. In addition to heart, kidney, lung, and spleen, fetal skeletal muscle and liver also contained WISP-1 RNAs. The WISP-3 RNAs were detected only in adult kidney and testis and in fetal kidney. No expression of the WISP genes was detected in brain. ${ }^{16}$ In situ hybridisation using whole mount mouse embryos and northern blot analysis of adult rat and mice organs could not detect rCOP1 RNA in brain, heart, lung, kidney, pancreas, spleen, intestine, stomach, and skeletal muscle. ${ }^{15}$ The expression of WISP-2 in human skeletal muscle was in contrast to the lack of expression of rCOP-1 in rodents.

Northern blot analysis of ctgf expression in normal adult tissues ${ }^{28}$ established that ctgf polyA RNAs were found abundantly in spleen, ovary, gastrointestinal tract, prostate, heart, and testis, and at a lower level in thymus, placenta, lung, skeletal muscle, kidney, and pancreas. No expression of ctgf was detected in brain, liver, and peripheral leucocytes. ${ }^{28}$ The lack of ctgf expression in brain was in contrast to the western blotting identification of a $40 \mathrm{kDa}$ CTGF protein in rat brain homogenates and the immunochemical detection of CTGF in the cerebral cortex, the white matter of spinal cord..$^{44}$ The strongest positive signal for CTGF detection was seen in astrocytes of the cerebral cortex, ependymal cells of the cerebral ventricle, tanycytes along the central canal of the spinal cord, and pyramidal cells in the cortical layers III and V.

RNase protection assays performed on total RNA from BALB/c mouse tissues established that cyr61 expression is highest in lung; moderate in heart, uterus, and skeletal muscle; and low in kidney, adrenal gland, testes, brain, and ovary. ${ }^{45}$

Altogether, these results (see table 2 for a summary) illustrated the diversity of those tissues in which expression of the CCN genes can be detected at different stages of development, reinforcing the current view that $\mathrm{CCN}$ proteins are involved in various biological processes. From table 2 it can be seen that NOV was the only CCN protein highly expressed in the brain. Indeed, in situ hybridisation and immunocytochemistry performed on developing human, chicken, and rat embryos confirmed that the expression of nov was tightly associated with nervous system differentiation and 
Table 2 Expression of CCN RNA in different species

\begin{tabular}{|c|c|c|c|c|c|c|c|c|c|c|c|c|c|c|c|c|c|}
\hline & $H$ & $B R$ & $P L$ & $L U$ & $L I$ & $S / M$ & $K$ & $P A$ & $S P$ & $T H$ & $P R$ & $T$ & $O V$ & $C O$ & $S / I$ & $L E U$ & $A D$ \\
\hline c-nov E & ++ & ++ & NT & - & - & + & + & NT & NT & NT & NT & NT & NT & NT & + & NT & NT \\
\hline c-nov A & - & ++ & NT & ++ & - & - & NT & NT & + & NT & NT & NT & NT & NT & NT & NT & NT \\
\hline h-nov E & - & + & - & - & - & NT & + & NT & NT & NT & NT & NT & NT & NT & - & NT & ++ \\
\hline h-nov A & ++ & ++ & - & + & - & + & + & ++ & + & - & ++ & ++ & + & + & + & + & NT \\
\hline ctgf & ++ & - & + & + & - & + & + & + & ++ & + & ++ & + & ++ & ++ & ++ & - & NT \\
\hline cyr61 & ++ & $+/-$ & NT & $+/-$ & - & ++ & + & - & - & NT & NT & $+/-$ & $+/-$ & NT & - & NT & + \\
\hline WISP-1E & + & - & NT & + & $+/-$ & $+/-$ & ++ & NT & NT & - & NT & NT & NT & NT & NT & NT & NT \\
\hline WISP-1A & $+/-$ & - & $+/-$ & $+/-$ & - & - & $+/-$ & $+/-$ & $+/-$ & - & - & - & ++ & - & ++ & - & NT \\
\hline WISP-2E & - & - & NT & + & - & - & - & NT & NT & - & NT & NT & NT & NT & NT & NT & NT \\
\hline WISP-2A & - & - & - & - & - & + & - & - & - & - & - & - & + & + & - & - & NT \\
\hline WISP-3E & - & - & NT & - & - & - & ++ & NT & NT & - & NT & NT & NT & NT & NT & NT & NT \\
\hline WISP-3A & - & - & - & - & - & - & ++ & - & - & - & - & + & - & - & - & - & NT \\
\hline rCOP-1E & - & - & NT & - & NT & - & - & - & - & NT & NT & NT & NT & NT & - & NT & NT \\
\hline
\end{tabular}

Origin of tissues: H, heart; BR: brain; PL, placenta; LU, lung; LI, liver; S/M, skeletal muscle; K, kidney; PA, pancreas; SP, spleen; TH, thymus; PR, prostate; T, testis; OV, ovary; CO, colon; S/I, small intestine; LEU, leukocytes; AD, adrenal.

c-nov, chicken nov RNA; h-nov human nov RNA; E, embryonic; A, adult; NT, not tested.

Table 3 Distribution of nov transcripts in 10 week human embryo

\begin{tabular}{llllll}
\hline Ectoderm & & Endoderm & & Mesoderm & \\
\hline Brain & ++ & Gut endothelium & ++ & Adrenal cortex & +++++ \\
Spinal cord (mt,fp) & +++ & Bronchial epithelium & + & Kidney tubules & +++ \\
Cranial ganglia & +++ & Pancreatic ducts & + & Fusing skeletal muscle & +++ \\
Auditory apparatus & +++ & & & Gut smooth muscle & ++ \\
Dorsal root ganglia & +++ & & & Indifferent gonad & ++ \\
& & & & Meart & + \\
& & & & Pesonephros & + \\
& & & & & + \\
\hline
\end{tabular}

Data are from S Kocialkowski et al (2001, in press).

development (S Kocialkowsky et al, 2001, in press; G Chevalier et al, 2000, unpublished results; W Cai et al, 2000, unpublished results; Y Cherel et al, Proceedings of the first international workshop on the CCN family of genes, 17-19 October 2000, Saint-Malo, France).$^{46}$ The role and functions of NOV in the nervous system are under current investigation.

In situ hybridisation and immunocytochemistry performed on developing chicken embryos allowed us to establish the pattern of nov expression in kidney, muscle, nervous system, and skeletal development (G Chevalier et al, 2000, unpublished results). In general, a good match was seen between nov RNA and NOV protein detection. The expression of nov was detected at embryonic days 3 and 4 (E3 and E4) in the mesonephric mesenchyme, epithelial vesicles, and glomeruli. At later stages (E6 to E12), differentiated tubules were found to be positive for nov. Metanephric epithelial vesicles, glomeruli, and ureteric bud were also positive for nov until E14. From E4 onwards, developing myotome and skeletal muscle stained positive for nov. Nov expression was also detected in smooth muscle cells and cardiomyocytes. The nervous system was found to be strongly positive for nov. At early stages (E3) neuroepithelium was positive at E3, and at later stages (E3-E7) neural tube also showed strong staining for nov. In agreement with our previous detection of high amounts of NOV protein in human neuronal cells and axons, ${ }^{35}$ high concentrations of NOV protein were detected in chicken neuronal cells, which express low amounts of nov RNA, therefore reinforcing the possibility that in these cells, as well as in podocytes, the NOV protein accumulates or is stabilised. ${ }^{35}$ Because nov shares identity with the fruit fly axon repellent slit protein, the detection of nov along the chicken and human axons suggests that it might be involved in axonal guidance. Strong expression of nov RNA and proteins was also detected at sites of chondrogenesis, where it is probably involved in the late stages of chondrocyte differentiation and osteogenesis (see below).

In situ hybridisation and immunocytochemistry established that although the distribution of nov RNA and protein was widespread in first trimester human embryos (table 3), the major sites of nov expression included the central nervous system, the adrenal cortex, and differentiating muscle and kidney (S Kocialkowsky et al, 2001, in press). In all cases, the NOV protein was predominantly cytoplasmic, and weak staining of the extracellular matrix (ECM) was also seen in some instances. In general, there was a fairly good correlation between nov RNA and NOV protein expression, suggesting that nov acts locally rather than distantly. In agreement with results obtained at later developmental stages, ${ }^{46}$ neurones of both the spinal cord and the brain expressed high amounts of nov RNA and the NOV protein was clearly detected in cell bodies and axons. The floor plate of the spinal cord, spinal nerves, and dorsal root ganglia were identified as sites of abundant nov expression.

Muscle was the predominant mesodermal component expressing nov. Myotubes and fusing myoblasts were identified as major sites of nov expression in skeletal muscle. Smooth muscle also expressed nov, but to a lesser extent. At the early stages, cartilage chondrocytes did not express nov, whereas in the older embryo, the NOV protein was demonstrated in the perichondrium and in hypertrophic chondrocytes in the head, ribs, and lower limbs. In the developing urogenital tract, major discrepancies were noted between NOV protein and nov RNA values, suggesting that the NOV protein might accumulate at these sites for a particular function, although we cannot exclude, as yet, that nov RNA species are short lived in these cells. For instance, the concentrations of NOV protein in the podocytes of both mesonephric and metanephric glomeruli are usually extremely high, whereas in the same cells nov RNA species are barely detectable ( $\mathrm{S}$ Kociazlkowski et al, 2001, in press; G Chevalier et al, 2000, unpublished results). ${ }^{35}$ Because the NOV protein is fairly stable in the conditioned 
medium of NOV producing cells (B Perbal, 2000 , unpublished results), ${ }^{35}$ the raised concentrations of NOV detected in podocytes probably results from its accumulation. Whether this accumulation results from its interaction with other proteins at this site or is physiologically important (needed for glomeruli filtration?) remains to be established. The metanephric mesenchyme was strongly positive for nov RNA expression, with increasing staining as differentiation proceeds in the $S$-shaped bodies, and a dramatic decrease once glomeruli differentiation was achieved. These results were of particular interest because they strongly suggested that nov expression was tightly coupled to the differentiation process in these cells. Examination of immunocytochemical labelling in the heart indicated that at these stages the endocardium was negative for nov, although it is in close contact with the myocardium, an abundant source of NOV protein. This observation provided evidence that the NOV protein acts where it is produced rather than being transported and accumulating at a distant site. Among endodermal derived tissues, the gut mucosa, bronchial epithelium, and pancreatic ducts were positive for nov (table 3).

The immunocytochemical localisation of CYR61 and FISP12 proteins during mouse embryogenesis showed similarities and differences that were indicative of differential actions in development. ${ }^{47}$ The localisation of CYR61, but not FISP12, in limb bud mesenchyme in vivo and in vitro had suggested that CYR61 might be involved in chondrogenesis. ${ }^{47}{ }^{48}$ Purified CYR61 protein was indeed shown to promote the initial cell aggregation responsible for mesenchymal condensation before chondrogenic differentiation and to enhance the synthesis of cartilage specific matrix. ${ }^{49}$ More recently, it has been reported that in rat, cyr61 is expressed in a time dependent manner in mesenchyme cells and osteoblasts from fracture callus, ${ }^{50}$ whereas conventional in situ hybridisation did not detect cyr61 mRNA in normal bone. In the hFOB human osteoblast cell line, cyr61 was identified as a greatly upregulated gene by various factors important for bone metabolism such as $1,25(\mathrm{OH}) 2$ vitamin $\mathrm{D} 3$, tumour necrosis factor $\alpha$ (TNF$\alpha$, EGF, basic FGF, and interleukin $1 \beta$ (IL-1 $\beta){ }^{39}$

Differential display PCR identified ctgf as being preferentially expressed in HGS-2/8 human chondrosarcoma derived chondrocytic cells. ${ }^{51}$ In situ hybridisation established that ctgf was specifically expressed in the hypertrophic chondrocytes of costal cartilage and vertebral column in 17 day old mouse embryos, ${ }^{51}$ at a time when cyr61 expression is strongly downregulated, ${ }^{48}$ suggesting that CYR61 and CTGF might have complementary but different functions. Staining of the cost-chondral junctions of newborn mouse ribs indicated that ctgf was expressed in chondrocytes of the hypertrophic zone, but not in the proliferating and resting zone..$^{52}$ Osteoblasts did not express ctgf. Because ctgf mRNA expression was stimulated in $\mathrm{HCS} 2 / 8$ cells treated with TGF $\beta$ and bone morphogenic protein 2 (BMP-2), two factors believed to be involved in cartilage and bone formation, it was proposed that CTGF was a mediator of these cytokines in cartilage. Because CTGF promoted the proliferation and differentiation of chondrocytes in culture, ${ }^{53}$ it was proposed that ctgf expression is involved in endochondral ossification by acting on proliferating and maturating chondrocytes in growth cartilage. Both chondrocytic and osteoblastic cells express a $280 \mathrm{kDa}$ protein that has been described as a receptor for CTGF. ${ }^{54} 55$

Because nov expression was also detected in sites of chondrogenesis during chicken development (fig 8), we postulated that the negative regulatory activity attributed to nov (see above) might be involved at later stages of differentiation to counterbalance the stimulatory effects of CYR61 protein on chondrogenesis, which had been established in micromass cell cultures. $^{49}$ According to this view, CYR61 and NOV protein activities might represent the "yin and the yang" along common regulatory pathways leading to chondrocyte differentiation and osteogenesis.

To assess the potential role of nov in chondrogenesis and osteogenesis, we first analysed the expression of nov chicken during wing and leg development. ${ }^{56}$ Northern blotting performed on total RNA prepared from limb buds dissected between E4 and E18 established that expression of nov increasing significantly between E8 and E10 and progressively decreased until E14, to reach a basal value at E15. ${ }^{56}$ The expression profile of nov correlated with the time course of limb development, which is completed after 10 days of incubation under normal conditions. Sustained expression indicated that nov was required over an extended period of time during limb development, therefore suggesting that it might be needed for later events. Immunocytochemistry performed on paraffin wax embedded wing bud sections established that nov was mainly detected at E6 in the proliferating chondrocytes and the perichondrium (fig 9A), whereas at E11/E12, staining of nov was essentially detected in the hypertrophic chondrocytes of the central diaphyseal region and to a lower extent in the perichondrium (fig 9B). At E14, nov labelling was greatly reduced and restricted to a few hypertrophic chondrocytes in the developing wing. Flattened chondrocytes were not positive for nov expression at any stage of development (fig 9C). Pretreatment of the sections with hyaluronidase resulted in additional widespread labelling of the cartilaginous matrix, in agreement with nov being associated with the ECM. ${ }^{57}$ Similarly, CYR61 and CTGF were also reported to be ECM associated proteins and suggested to mediate cell-matrix interactions. $^{58}$

When mesenchymal cells isolated from the limb buds of 3.5 day old chicken embryos or from 10.5 day old mouse embryos are seeded at high density $\left(10^{7}\right.$ cells $\left./ \mathrm{ml}\right)$, cellular aggregation proceeds and internodular condensations undergo chondrocytic differentiation, as shown by the formation cartilaginous nodules within 


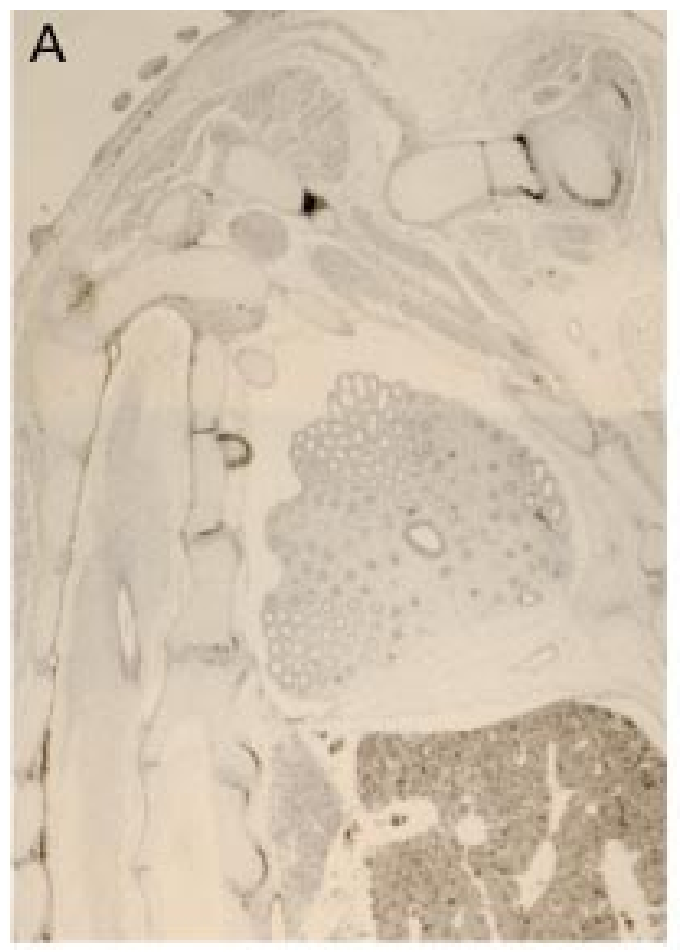

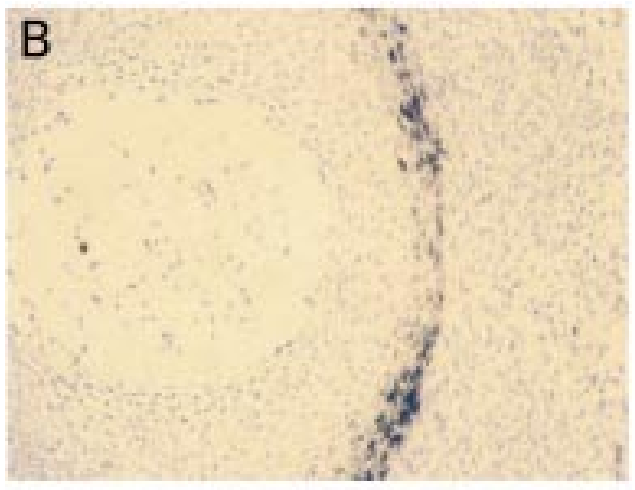

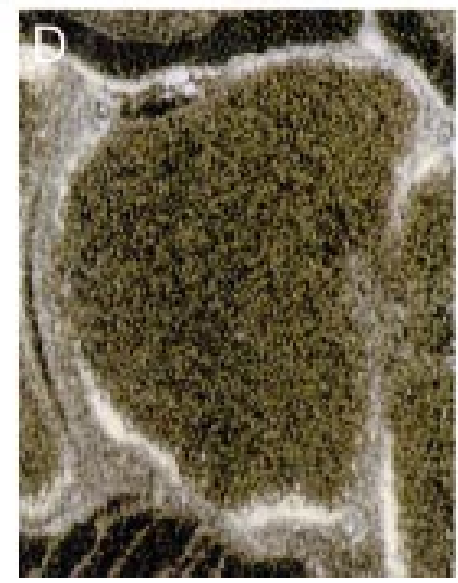

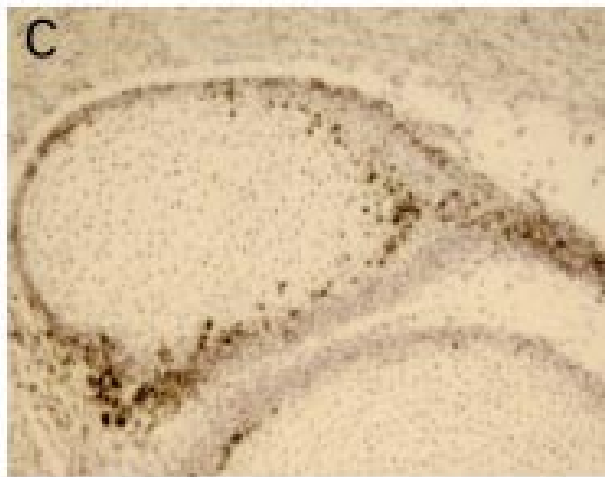

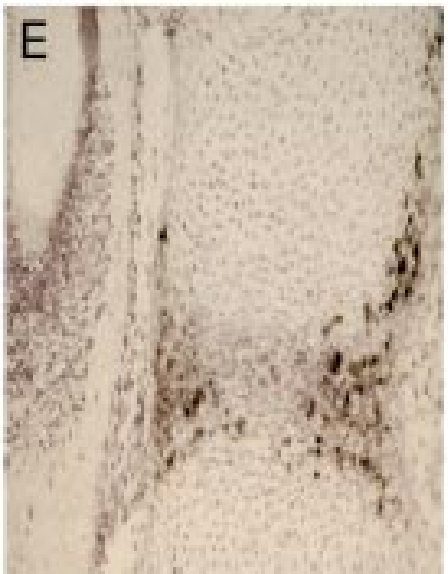

Figure 8 Detection of nov RNA species at sites of chondrogenesis in developing chicken. (A) Development stage (St) 3 , embryonic day (E) 8.5. (B) St 31, E7. (C) St 35, E8.5. (D) St 38, E12. (E) St 35, E8.5.

three days of culture. When cells are seeded at a lower density $\left(10^{6} / \mathrm{ml}\right)$, chondroblastic differentiation does not proceed and no cartilaginous formation occurs. The use of this system revealed that CYR61 enhances chondrogenic differentiation. ${ }^{49}$ Northern blotting experiments performed on chicken micromass cell cultures established that nov expression, which was not detected at day 0 of culture, increased progressively for two days and decreased at day 3 , whereas the expression of collagen II, a marker for determination of progenitor cells to undergo chondroblastic differentiation, increases from day 1 onwards (fig 10). The 

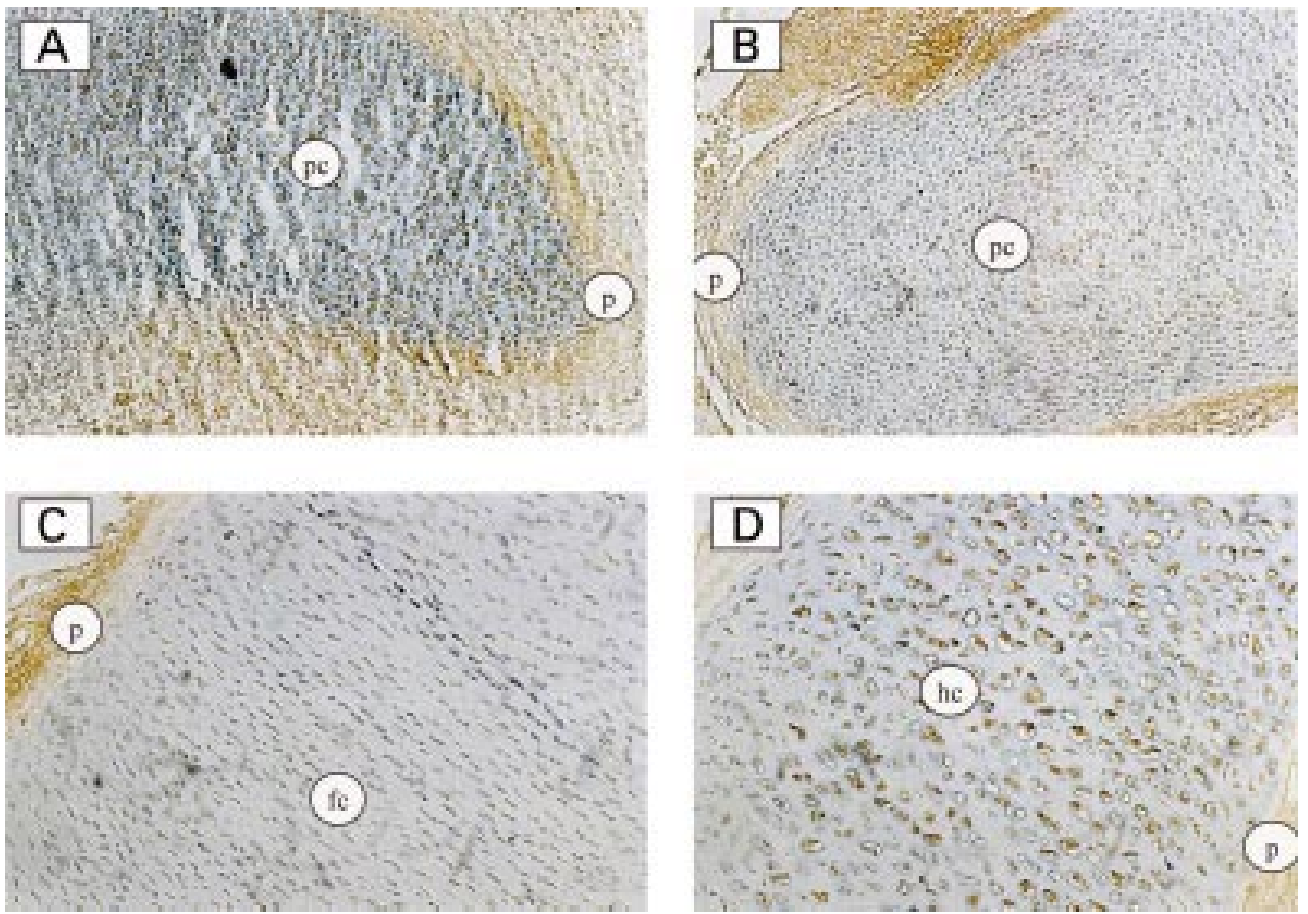

Figure 9 Detection of the NOV protein in developing bone. (A) At stage 29 (embryonic day 6 (E6)), NOV is detected at sites of chondrogenesis in the developing chicken wing. Alcian blue staining identifies cartilage formation. (B) At stages 35-38 (E11-12) strong nov staining is seen in the perichondrium (p) and proliferating chondrocytes $(p c)$. (C) At the same stages, flattened chondrocytes $(f c)$ do not stain positive for nov, whereas hypertrophic chondrocytes (hc) are strongly positive for NOV staining (D).

expression of nov is dependent upon the productive differentiation of mesenchyme cells, as shown by the lack of nov expression in the absence of cartilaginous nodule formation at low cell density (fig 11). When cells were seeded at high density, ctgf expression was detected in micromass cultures from day 2 onwards, whereas CEF10 expression was detected from day 0 to day $3 .{ }^{49}$
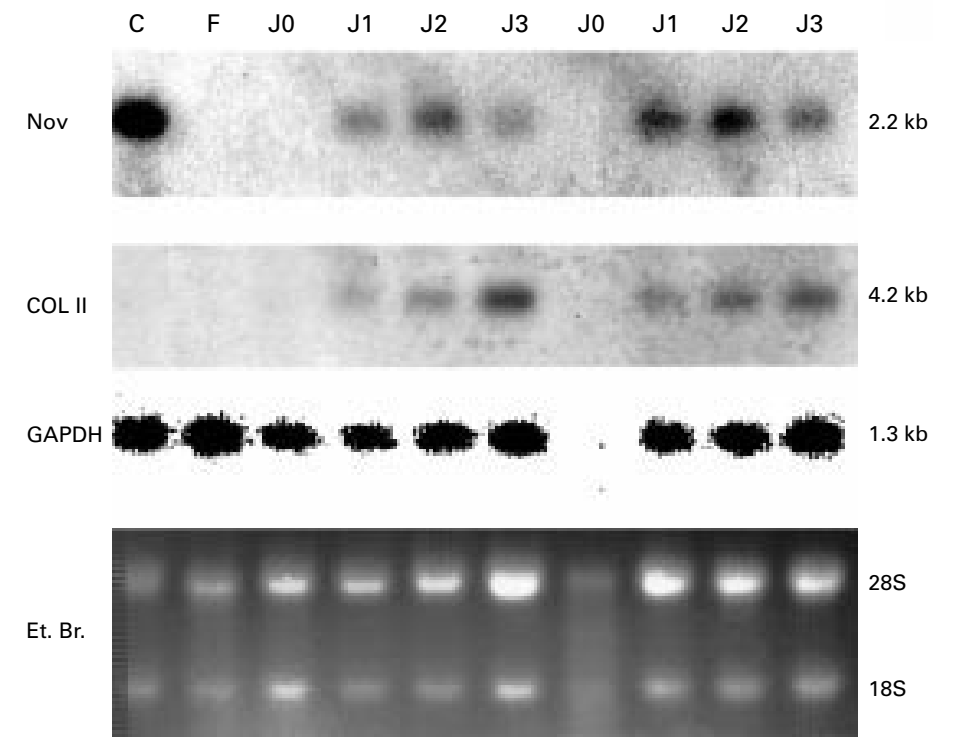

Figure 10 Expression of nov RNA species and collagen II (COL II) in chicken micromass cell cultures. Staining of ribosomal RNA species allows relative quantification of the hybridisation signals obtained in two independent experiments. ${ }^{56}$ 70-73, days of culture; GAPDH, glyceraldehyde-3-phosphate dehydrogenase.
These observations and the results of immunochemical studies performed on sections suggested that NOV and CTGF were required at late stages of the chondrogenesis/osteogenesis differentiation process, whereas CYR61 was required at early stages. Whether the differential expression of these three CCN genes in the skeletal system is temporally related remains to be established.

It is worth noting that in addition to nephroblastoma, MAV can induce osteopetrosis in chickens, an abnormal proliferation of osteoblasts leading to severe bone diseases. ${ }^{10}$ Based on the consideration that nov was a target of MAV in chicken blastemal cells, it is tempting to hypothesise that the induction of osteopetrosis by MAV could also result from an alteration of nov expression in bone precursor cells.

EXPRESSION PATTERN IN PATHOLOGICAL CONDITIONS

Evidence indicating that $\mathrm{CCN}$ proteins participate in various diseases has been accumulating at an increasing pace over the past years.

The relation that was established between ctgf expression and TGF $\beta$ has resulted in considerable interest in the potential role of CTGF in fibrosis and its possible medical applications. This has led to the widely accepted conclusion that the profibrogenic properties of TGF $\beta$ result from ctgf induction, stimulation of fibroblast proliferation, and overproduction of extracellular matrix. As discussed in depth by Essam et $a l,{ }^{4}$ the relation between ctgf and TGF $\beta$ expression is not absolute and there are 


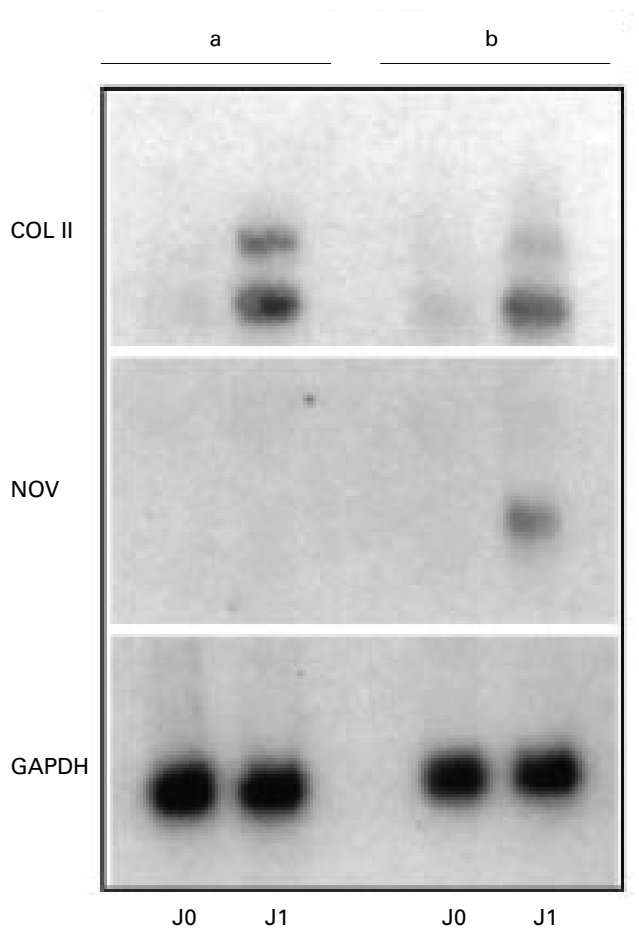

Figure 11 The expression of nov RNA depends upon chondrogenesis. (A) $10^{6}$ mesenchymal cells were seeded for micromass cell cultures. (B) $10^{7}$ mesenchymal cells were seeded for micromass cell cultures. Samples were taken at the day of seeding (FO) and after 24 hours culture (F1). COL II, collagen II; GAPDH, glyceraldehyde-3-phosphate dehydrogenase.

several studies indicating that ctgf expression may be independent of TGF $\beta$ in fibroblasts.

Nonetheless, ctgf expression is involved in many types of diseases, including fibrotic diseases, atherosclerosis, inflammatory diseases, and scleroderma. The expression of ctgf also increases in wound healing. Because these aspects of CTGF biology have been reviewed extensively, ${ }^{2-4} \mathrm{I}$ will focus on studies that identify CCN proteins as key players in tumour development.

For many years, the only evidence suggesting that CCN genes might be involved in cancer development came from studies performed with nov.

Because nov was originally shown to be highly expressed in all avian nephroblastomas, we initiated studies aimed at establishing whether nov expression was also altered in human Wilms's tumours and whether an alteration of nov expression was associated with other types of tumours. These studies were conducted with two hopes, namely: (1) that measurement of nov in biological fluids or in tumours might be of clinical value for early diagnosis, typing, and prognosis; and (2) that the antiproliferative activity of nov could be used in cancer treatment.

The studies that we have performed with Wilms's tumours established that they contained abnormal amounts of nov RNA, which were in some cases inversely related to that of the WT1 RNAs detected in the same samples, ${ }^{59}$ an observation that, at first glance, was in agreement with the ex vivo downregulation of nov promoter activity by WT $1 .{ }^{39}$ However, studies performed with a larger panel of samples $^{35}$ representative of sporadic, Wilms, aniridia, growth retardation (WAGR) and Denis Drash syndrome (DDS) histological types of tumours did not confirm that inverse relation and raised the possibility that the variations of nov expression resulted from different relative amounts of WT1 isoforms contained in these tumours. ${ }^{35}$

These studies also established that nov expression was a marker of heterotypic differentiation..$^{35}$ In striated muscle tumours, the expression of nov was shown to occur at an earlier stage than desmin during the heterotypic differentiation of the blastemal cells that takes place in these tumours, ${ }^{35}$ and confocal microscopy established that the NOV protein was colocalised with desmin in heterotypic muscle fibres (G Chevalier, 1998, unpublished observation).

Studies that we have performed with several other types of tumours have established a strong association between nov expression and tumour differentiation in rhabdomyosarcomas, neuroblastomas, and cartilage tumours $(\mathrm{H}$ Yeger et al, and C Yu et al, Proceedings of the first international workshop on the CCN family of genes, 17-19 October 2000, Saint-Malo, France). In the case of neuroblastomas with poor prognostic features, nov staining was low/ moderate within the small tumour cells, whereas in tumours with a favourable prognosis and no N-myc amplification, nov staining was strong in the cytoplasm of differentiated ganglion-type cells (H Yeger et al, 1998, unpublished results). These results indicated that nov expression can be used as a valuable molecular marker for neuroblastoma typing and for tumour prognosis.

Because the adrenal was identified as a major site of nov expression in the human embryo (see above), and because there is no molecular prognosis factor for adrenocortical carcinoma, we examined whether alterations in nov expression occurred in these highly lethal cancers with a mortality rate over $50 \%$. In the normal adult adrenal cortex, immunocytochemical studies showed a distinct positive labelling for nov in the zona fasciculata, the middle layer of the adrenal cortex. The labelling was fairly uniform and confined to the cytoplasm (fig $12 \mathrm{~A})$. In the adrenocortical adenomas there was clear staining of nov in cells that probably mimic the zona fasciculata (fig 12B). However, staining in the adenomas was not homogenous, therefore suggesting that the amount of nov detected in the cells of these benign tumours was dependent upon their metabolic state or was related to hormone production. Adrenocortical carcinomas stained either negative (fig $12 \mathrm{C}$ ) or positive for nov. No clearcut relation could be established between the degree of nov expression and tumour stage.

In pronounced contrast and apparent contradiction to these reports, our studies also established that the expression of nov correlated with the metastatic potential of tumour cells in the case of Ewing's sarcomas (MC 

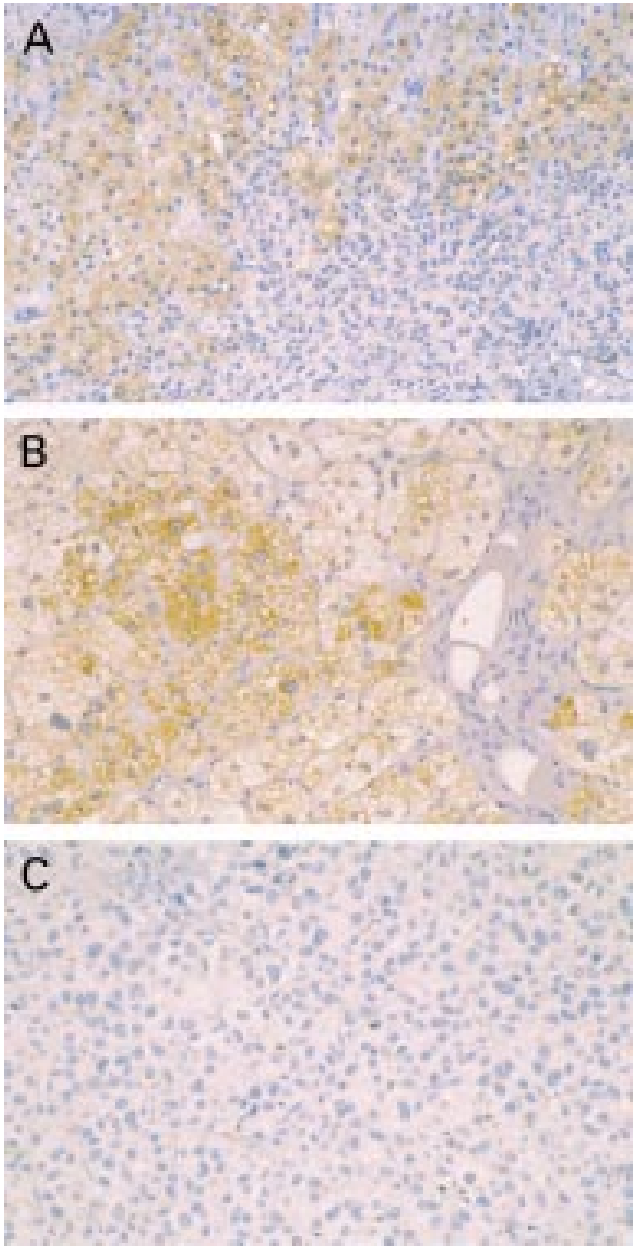

Figure 12 Detection of the NOV protein in normal $(A)$ and tumoral adrenal tissues ( $B$ and $C$ ). The normal area was isolated from a patient with adenoma. Note the uneven nov staining in the adenoma $(B)$. An example of $N O V$ negative adrenal carcinoma is shown (C). Photographs were kindly provided by $H$ Yeger.

Manara et al, 2000, unpublished results), prostate cancer (B Cadot et al, Proceedings of the first international workshop on the CCN family of genes, 17-19 October 2000, submitted for publication) and renal cell carcinoma ( $\mathrm{L}$ Glukhova et al, 2001, submitted for publication; L Glukhova et al, Proceedings of the first international workshop on the CCN family of genes, 17-19 October 2000, submitted for publication). In addition to the labelling of NOV in the cytoplasm of acinar epithelial cells, prostate hyperplasia showed intense luminal labelling suggestive of NOV secretion in seminal fluid. Whether measurement of NOV in seminal fluid can be of value as a marker of prostate disease is currently being investigated. In prostate tumour cell lines, the expression of nov was detected in the cytoplasm of three cell lines derived from metastasis to bone (PC3), brain (DU145), and lymph node (LNCap). No expression was detected in the SV40-T antigen immortalised PNT1B cells, an observation in contrast to a recent study indicating that SV40-T immortalised P69 cells were positive for nov expression. ${ }^{60}$ In renal cell carcinomas (RCCs), which represent $85-90 \%$ of all kidney tumours, a significantly higher concentration

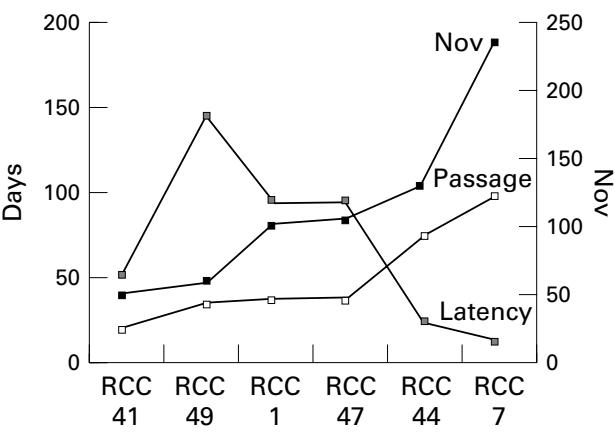

Figure 13 Expression of nov in renal cell carcinomas (RCCs). Increased amounts of nov were correlated with increased tumorigenicity. Nov, levels of nov RNA estimated from northern blots; Latency, time in days required to reach a tumour of a given size.

of secreted NOV protein was detected by western blotting in the conditioned medium of fast growing tumours. These results indicated that there was an inverse relation between the amount of NOV secreted by the tumour cells and the time that they required to establish tumours in vivo and for the tumour to reach a given size (fig 13).

Finally, results that were obtained in our study of glioblastoma cell lines suggested that nov expression was correlated with reduced tumorigencity and reduced metastatic potential in these brain tumour cells. ${ }^{61}$ Whether we can use the negative growth regulatory properties attributed to nov as a tool for treatment of these highly aggressive tumours is currently the matter of intense investigation.

Therefore, it appeared that the expression of nov was altered in many types of tumours and that high concentrations of NOV could be associated with either differentiation or increased proliferation and metastasis. This complex and apparently conflicting situation is not unique to nov among the CCN proteins. As reported above: (1) the WISP genes whose expression is upregulated in Wnt transformed cells are either upregulated or downregulated in colon cancers, and (2) the expression of WISP-1 increased the tumorogenicity of transfected cells whereas overexpression of Elm1 had opposite effects.

It is widely accepted that the establishment and development of tumours rely on the ability of the tumour cells to overcome hypoxia and establish a network of blood vessels that will ultimately permit the tumour to expand. Neovascularisation is therefore controlled by the tumour cells that secrete angiogenic factors to attract endothelial cells, which in turn are believed to produce growth factors stimulating tumour growth. Several positive and negative regulators of angiogenesis have been described. The angiogenic properties of CYR61 and CTGF $^{2}{ }^{62}{ }^{63}$ suggest that these proteins might be involved in tumour growth. Indeed, gastric adenocarcinoma RF-1 cells transfected with cyr61 gave rise to larger and more vascularised tumours than parental cells when injected into nude mice. ${ }^{62}$ Many tumour cell lines were reported to express cyr61 at various levels. Although it was reported that cyr61 expressing tumour cells were more tumorigenic than those 
that did not express this gene, ${ }^{2}$ no clearcut association of this kind was drawn from studies that we performed with glioblastoma cell lines. ${ }^{64}$ Downregulation of cyr61 expression was reported in rhabdomyosarcomas, ${ }^{65}$ and in about $50 \%$ of prostate tumours samples, ${ }^{66}$ whereas increase expression of cyr61 has been detected in pancreatic cancers (C Wenger and TM Gress, Proceedings of the first international workshop on the CCN family of genes, 17-19 October 2000, Saint-Malo, France) and in about $30 \%$ of invasive breast carcinomas. ${ }^{67}$

Increased expression of ctgf has also been detected by northern blotting in about $70 \%$ of 11 human invasive mammary ductal carcinomas, ${ }^{68}$ in $100 \%$ of nine dermatofibromas examined, in pyogenic granuloma, in endothelial cells of angiolipomas and angioleiomyomas, ${ }^{69}$ and in 15 of 19 pancreatic tumours. ${ }^{70}$ However, five of seven cases of dermatofibrosarcoma protuberans and two cases of malignant fibrous histiocytoma were negative for ctgf expression. ${ }^{69} \mathrm{~A}$ more recent immunocytochemical study performed with 18 chondrosarcomas representative of various histological grades established that ctgf expression closely correlated with increasing malignancy. ${ }^{71}$

Although the number of reports concerning the expression of cyr61 and ctgf in tumours is still limited, the general picture is that neither a straightforward nor a general correlation can be drawn between the expression of cyr61 or ctgf and tumour development.

A clue to understanding the discrepancies observed for the expression of the CCN genes in cancer cells might come from the multimodular structure of the CCN proteins and their potential ability to interact sequentially or simultaneously with different partners, the bioavailability of which might be a key element in the manifestation of the positive or negative effects attributed to the CCN proteins. In line

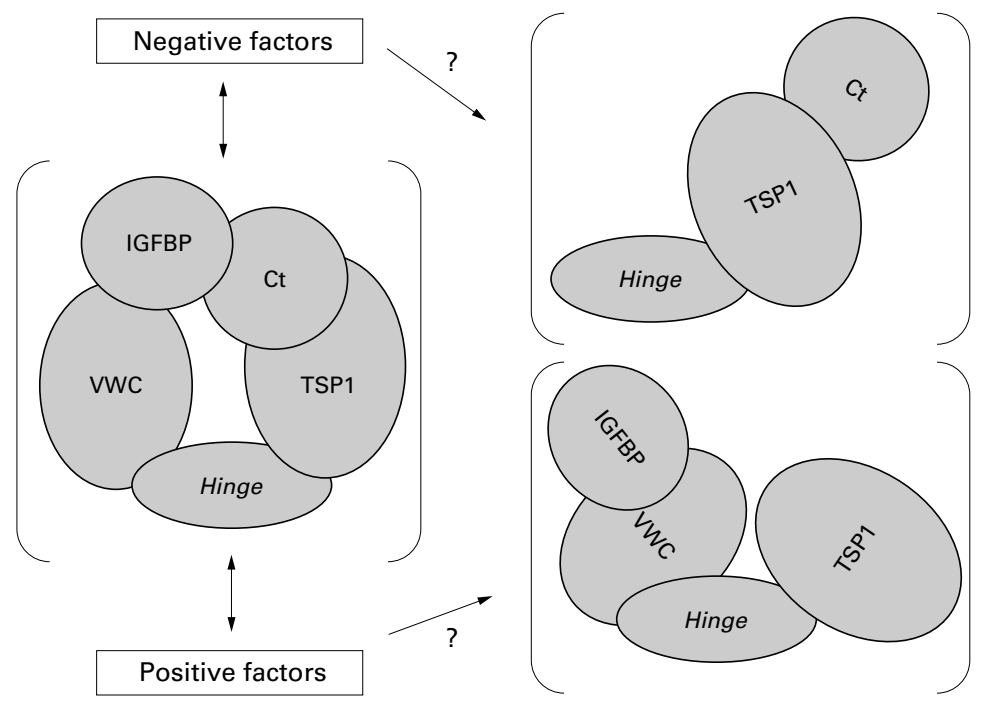

Figure 14 Model for the structural organisation of the CCN proteins. Potential interactions with positive and negative regulators are thought to be disrupted upon truncation of the N-proximal and C-proximal modules of CCN proteins. Ct, cystein knot containing family of growth regulators-like domain; IGFBP, insulin-like growth factor binding protein-like domain; TSP1, thrombospondin-like domain; and VWC, Von Willebrand factor-like domain. with this, I would like to propose that the biological activity of the CCN proteins is dependent upon different combinatorial effects. Therefore, a search for proteins and ligands interacting with nov has been undertaken.

\section{Identification of $\mathrm{CCN}$ protein partners}

As a first step in identifying the proteins that might interact with NOV and other CCN proteins we have used ${ }^{30} 33$ the two hybrid system strategy, which has been used successfully over the past few years to uncover many protein interactions involved in cell growth signalling.

To avoid selecting targets that might only interact with isolated modules, we used the full length NOV protein fused to the DNA binding domain of Gal4 DNA as bait. The interactions that were detected with this system were usually validated by pull down assays performed with a panel of glutathione S-transferase (GST) fusion proteins containing different portions of nov. The use of these recombinant proteins also allowed us to identify the domains of NOV that were involved in the interactions.

In addition to RNA polymerase II subunit $7,^{30}$ we identified fibulin $1 \mathrm{C}$ as a protein interacting with NOV. ${ }^{33}$ The potential interaction of NOV and fibulin $1 \mathrm{C}$ provided the first evidence for a role of NOV in cell adhesion signalling. Fibulin $1 \mathrm{C}$ is a $100 \mathrm{kDa}$ protein of the ECM that has been reported to bind fibronectin, laminin, fibrinogen, and basement membrane protein nidogen. ${ }^{33}$ The expression of fibulin 1 in the perichondrium and calcifying regions of developing bones, in the gut subepithelium, and in peripheral nerves of human embryos of gestational weeks 4-10 correlated with sites of nov expression at the same developmental stages, and provided another indication that NOV and fibulin might indeed interact in vivo. Furthermore, the levels of nov and fibulin 1C RNAs correlated inversely in several cell lines, ${ }^{33}$ and ectopic expression of nov is accompanied by a decrease of fibulin 1C concentrations, therefore suggesting that a downregulation of fibulin 1C transcription might take place in cells expressing high amounts of nov.

These studies also established that the C-terminal module of NOV was sufficient to promote the interaction of NOV with fibulin 1C. The association of NOV and fibulin through the C-terminal portion of fibulin 1C, which contains five of nine EGF repeats present in fibulin $1 \mathrm{C}$, raised the possibility that the binding of NOV might mediate the potential role of fibulin $1 \mathrm{C}$ in the assembly of the ECM and cell adhesion. ${ }^{33}$ It is worth noting that the C-terminal domain of NOV was also shown to mediate the interaction of NOV with CTGF in the two hybrid system, therefore suggesting that heterodimerisation of $\mathrm{CCN}$ proteins might take place in vivo and that cross talk between CCN proteins is involved in the modulation of their biological activities. CCN proteins such as rCOP1 and CTGF-L, ${ }^{72}$ which are deprived of the C-terminal domain, might play an important role in these processes and exhibit a whole range of dominant negative type activities. 
Full length

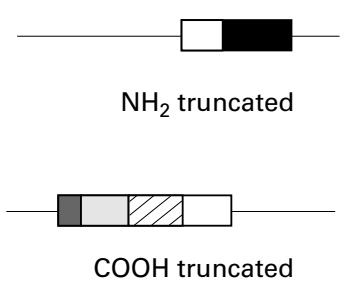

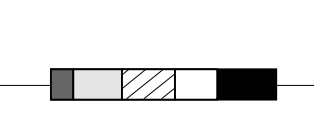

Upregulated, suppressor nov

Unregulated, inducder wisp1

Downregulated, suppressor Elm1

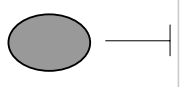

Upregulated oncogenic nov

Figure 15 CCN proteins and cancer. This schematic drawing summarises the diversity of situations encountered for CCN proteins in tumours. Whether the subcellular localisation of the CCN proteins other than NOV can result in opposing biological properties remains to be established.
Our working hypothesis is based on the assumption that under native conditions the CCN proteins adopt a compact structure (fig 14), where two halves interact with each other as a result of the hinge region that is found between modules 3 and 4 (sharing identity with von Willebrand factor type $\mathrm{C}$ repeat and thrombospondin, respectively). This interaction would permit the $\mathrm{N}$-proximal half to exert a negative regulatory control on the stimulatory properties of the C-proximal half. The folded structure would also allow a certain number of interactions with positive and negative effectors. The bioavailability of these effectors, coupled with the temporal and spatial expression of the $\mathrm{CCN}$ proteins, would be crucial factors that dictate the constitution of the complexes that can be formed, and subsequently the nature of the signals transmitted by these complexes. Truncations of the CCN proteins at either their $\mathrm{N}$-terminus or $\mathrm{C}$-terminus would disrupt these regulatory interactions, alter the balance of positive and negative regulatory signals (fig 15), and result in conferring to these proteins a constitutive repressive or stimulatory effect on cell growth, as exemplified by the case of WISP-2/rCOP 1 , and by the production of an oncogenic truncated NOV protein in MAV induced nephroblastoma (see above). The implications of this working model are presently being tested.

\section{Future directions and prospects}

In the light of the recent results reported in this review, it seems that CCN proteins might act as multipotent matchmakers, allowing the scaffolding of a complex network of regulatory proteins responsible for the regulation of several fundamental functions during normal life, development, and probably death.

The identification of other proteins potentially interacting with NOV has established that each of the four constitutive domains of the native protein is required alone or in combination with others to promote the interactions. In some cases, only the full length NOV protein was found to interact with potential targets. Deciphering this complex situation will certainly lead to the identification of major players responsible for the regulation of NOV biological activity. Establishing whether other CCN proteins also interact with the NOV targets remains a major goal.

More generally, there is a dramatic need for comparative studies to be performed with different members of the CCN family. The availability of the reagents and the development of biological assays for several members of the CCN family should greatly ease such studies, the potential value of which is obvious in the light of the diversity of the systems used thus far.

To answer the question "what is nov doing?" I have embarked my laboratory on a path aimed at examining several complementary aspects of nov biology. Similar approaches performed with other CCN genes would certainly prove to be extremely fruitful. Thus, I think it is essential to establish where, how, and with whom the CCN proteins act to answer later the questions regarding the regulation of their activity and the consequences of altered expression.

WHERE?

The use of different efficient expression systems (such as baculoviruses) enables the production of recombinant tagged proteins that can be used to identify the sites of CCN protein binding on cells and follow the fate of the secreted proteins once they are presented at the cell surface. The production of specific polyclonal and monoclonal antibodies directed against different portions of the CCN proteins also enables their concentrations to be measured in biological fluids. They can also establish whether quantitative variations of circulating CCN proteins are associated with pathological conditions and can be used as a valuable clinical tool. We are presently using this strategy to measure, under pathological conditions, the variations of NOV released in different biological fluids, such as cerebrospinal fluid, seminal fluid, urine, and serum.

How?

This aspect requires the purification of native $\mathrm{CCN}$ proteins from a reliable biological source. Although the use of recombinant proteins has proved very fruitful in unravelling the biological properties of several signalling effectors, it must be kept in mind that many biochemical properties of native proteins require post translational modifications, which do not take place (or only partially) in most of the systems used to produce recombinant proteins. Purification of the native protein also permits the isolation of functional complexes whose characterisation has proved to be extremely informative in many instances. Because CCN proteins potentially interact with several other partners, the isolation of complexes in which these proteins are engaged will undoubtely lead to important discoveries concerning their mode of action. The purification of the different $\mathrm{CCN}$ proteins can also establish whether they exhibit synergistic or antagonistic properties when tested in combination. 
WITH WHOM?

Immunoprecipitation of complexes, covalent crosslinking, and solid phase assays are among the biochemical strategies being used currently to identify ligands interacting with the CCN proteins. The use of biological systems such as phage display, the two hybrid system, etc should also permit the identification of proteins interacting with some, or many members, of the CCN family. Establishing whether cross interactions exist among the different CCN proteins will be of great interest.

Questions regarding the biological activity of the CCN proteins in vitro or ex vivo are also worth considering. There are several systems in which to study the effects of CCN proteins on proliferation, differentiation, and cell death. Again, comparative studies performed with different members of the CCN family in the same system should greatly improve our understanding of the biology of CCN proteins.

Post transcriptional and post translational processes are thought to be involved in the regulation of the bioavailability and functions of $\mathrm{CCN}$ proteins. PKC is involved in the regulation of CCN RNA post translational turnover. Activation of PKC has recently been reported to inhibit the expression of ctgf. ${ }^{73} \mathrm{It}$ would be worth examining more precisely the relation that might exist between PKC directed phosphorylation and CCN gene expression.

Last, but not least, the bulk of studies aimed at establishing whether the CCN proteins are involved, directly or indirectly, in tumour development have demonstrated the extreme complexity and diversity of CCN gene expression patterns in the various systems analysed. Again, comparative studies would certainly be very informative and would probably allow us to establish a solid basis for the understanding of the biological properties of the CCN proteins and to determine whether they can be used as tools for future molecular medicine.

I wish to thank particularly my wife Annick for her help and constant support. Thanks are also due to S Gabaron for reading the manuscript. The research performed in my laboratory was funded by grants from the Ligue Nationale Contre le Cancer (Comités National, du Cher et de l'Indre), Associntion (Comites National, du Cher et de I'Indre), Association Française contre les Myopathies (AFM), Matra-Hachettte, Fondation pour la Recherche Médicale (FRM), and Association pour la Recherche contre le Cancer (ARC). I am grateful to ity to perform experiments with herpes simplex virus and the two hybrid system.

1 Bork P. The modular architecture of a new family of growth regulators related to connective tissue growth factor. FEBS regulators related to con

2 Lau LF, Lam SC. The CCN family of angiogenic regulators: the connection. Exp Cell Res 1999; 248:44-57.

3 Brigstock DR. The connective tissue growth factor/cysteinerich 61/nephroblastoma overexpressed (CCN) family. Endocr Rev 1999;20:189-206.

4 Essam ED, Moussad A, Brigstock D. Connective tissue growth factor: what's in a name. Mol Genet Metab 2000;71 276-92.

5 Lau LF, Nathans D. Expression of a set of growth-related immediate early genes in $\mathrm{BALB} / \mathrm{c}$ 3T3 cells: coordinate regulation with c-fos or c-myc. Proc Natl Acad Sci USA $1987 ; 84: 1182-6$

6 Almendral J, Sommer D, Mac Donald-Bravo H, et al. Complexity of the early genetic response to growth factors in mouse fibroblasts. Mol Cell Biol 1998;8:2140-8.

7 Brunner A, Chinn C, Neubauer M, et al. Identification of a gene family regulated by transforming growth factor- $\beta$. DNA Cell Biol 1991;10:293-300.

8 Matsunaga E. Genetics of Wilms' tumor. Hum Genet 1981; 57:231-46.

9 Perbal B. Contribution of MAV-1-induced nephroblastoma to the study of genes involved in human Wilms' tumor development. Crit Rev Oncog 1994;5:589-613.
10 Perbal B. Pathogenic potential of myeloblastosis associated viruses. Infect Agents Dis 1995;4:212-27.

11 Chevalier G, Perbal B. Genetic alterations associated with pathologic differentiation of Wilms' tumors. Bull Cancer (Paris) 1997;84:289-303.

12 Joliot V, Martinerie C, Dambrine G, et al. Proviral rearrangements and overexpression of a new cellular gene (nov) in myeloblastosis-associated virus type 1-induced nephroblastomas. Mol Cell Biol 1992;12:10-21.

13 Martinerie C, Viegas-Péquignot E, Guénard I, et al. Physical mapping of human loci homologous to the chicken nov protooncogene. Oncogene 1992;7:2529-34.

14 Hashimoto BY, Shindo-Okada N, Tani M, et al. Expression of the ELM1 gene, a novel gene of the CCN (connective tissue growth factor, cyr61/cef10, and neuroblastoma overexpressed gene) family, suppresses in vivo tumor growth and metastasis of K-1735 murine melanoma cells. F Exp Med 1998;187:289-96.

15 Zhang R, Averboukh L, Zhu W, et al. Identification of rCop-1, a new member of the CCN protein family, as a negative regulator for cell transformation. Mol Cell Biol 1998;18:6131-41.

16 Pennica D, Swanson TA, Welsh JW, et al. WISP genes are members of the connective tissue growth factor family that are up-regulated in Wnt-1-transformed cells and aberrantly expressed in human colon tumors. Proc Natl Acad Sci U S A 1998;95:14717-22.

17 Simmons D, Levy D, Yannoni Y, et al. Identification of a phorbol ester-repressible v-w-c- inducible gene. Proc Natl Acad Sci USA 1989;86:1178-82.

18 Scholz G, Martinerie C, Perbal B, et al. Transcriptional down regulation of the nov proto-oncogene in fibroblasts transformed by p60v-src. Mol Cell Biol 1996;16:481-6.

19 Bradham DM, Igarashi A, Potter RL, et al. Connective tissue growth factor: a cysteine-rich mitogen secreted by human vascular endothelial cells is related to the SRCinduced immediate early gene product CEF-10. F Cell Biol 1991;114:1285-94.

20 Ryseck RP, Macdonald-Bravo H, Mattei MG, et al. Structure, mapping, and expression of fisp-12, a growth factor-inducible gene encoding a secreted cysteine-rich protein. Cell Growth Differ 1991;2:225-33.

21 Lin J, Liliensiek B, Kanitz M, et al. Molecular cloning of genes differentially regulated by TNF- $\alpha$ in bovine aortic endothelial cells, fibroblasts and smooth muscle cells. Cardiovasc Res 1998;38:802-3.

22 Steffen CL, Ball-Mirth DK, Harding PA, et al. Characterisation of cell-associated and soluble forms of connective tissue growth factor (CTGF) produced by fibroblast cells in vitro. Growth Factors 1998;15:199-213.

23 Igarashi A, Okochi H, Bradham DM, et al. Regulation of connective tissue growth factor gene expression in human skin fibroblasts and during wound repair. Mol Cell Biol 1993;4:637-45.

24 Hishikawa K, Oemar BS, Tanner FC, et al. Overexpression of connective tissue growth factor gene induces apoptosis in human aortic smooth muscle cells. Circulation 1999;100: $2108-112$.

25 Hishikawa K, Oemar BS, Tanner FC, et al. Connective tissue growth factor induces apoptosis in human breast cancer cell line MCF-7. F Biol Chem 1999;274:37461-6.

26 Hishikawa K, Nakaki T, Fujii T. Connective tissue growth factor induces apoptosis via caspase 3 in cultured human aortic smooth muscle cells. Eur f Pharmacol 2000;392:19-

27 Hurvitz JR, Suwairi WM, Van Hul W, et al. Mutations in the $\mathrm{CCN}$ gene family member WISP3 cause progressive pseudorheumatoid dysplasia. Nat Genet 1999;23:94-8.

28 Kim HS, Nagalla SR, Oh Y, et al. Identification of a family of low-affinity insulin-like growth factor binding proteins (IGFBPs): characterisation of connective tissue growth factor as a member of the IGFBP super family. Proc Natl Acad Sci U S A 1997;94:12981-6.

29 Grotendorst G, Lau L, Perbal B. CCN proteins are distinct from and should not be considered members of the insulin-like growth factor-binding protein superfamily. Endocrinologie 2000;141:2254-6.

30 Perbal B. Nuclear localization of NOV protein: a potential role for nov in the regulation of gene expression. $7 \mathrm{Clin}$ Pathol: Mol Pathol 1999;52:84-91.

31 Roizman B, Sears A. Herpes simplex viruses and their replication. In: Fields BN, Knipe DM, eds. Fields virology, Vol. 2. New York: Raven Press, 1990:1795-841.

32 Mahony D, Kalionis B, Antalis TM. Plasminogen activator inhibitor type-2 (PAI-2) gene transcription requires a novel NF-KappaB-like transcriptional regulatory motif. Eur $\mathcal{F}$ Biochem 1999;263:765-72.

33 Perbal B, Martinerie C, Sainson R, et al. The C-terminal domain of the regulatory protein $\mathrm{NOVH}$ is sufficient to promote interaction with fibulin 1C: a clue for a role of NOVH in cell-adhesion signaling. Proc Natl Acad Sci U S A 1999;96:869-74.

34 Ball DK, Surveyor GA, Diehl JR, et al. Characterisation of 16-to 20-kilodalton $(\mathrm{kDa})$ connective tissue growth factors (CTGFs) and demonstration of proteolytic activity for 38-kDa CTGF in pig uterine luminal flushings. Biol Reprod 1998;59:828-35.

35 Chevalier G, Yeger H, Martinerie C, et al. NovH: differential expression in developing kidney and Wilms' tumors. Am 7 Pathol 1998;152:1563-75. 
36 Burren C, Wilson E, Hwa V, et al. Binding properties and distribution of insulin-like growth factor binding proteinrelated protein 3 (IGFBP-rP3/NovH), an additional mem-
ber of the IGFBP superfamily. F Clin Endocrinol Metab ber of the IGFBP

37 Latinkic B, O'Brien P, Lau L. Promoter function and structure of the growth factor-inducible immediate early gene cyr61. Nucleic Acids Res 1991;19:3261-7.

38 Grotendorst G, Okochi $\mathrm{H}$, Hayashi N. A novel transforming growth factor $\beta$ response element controls the expression of the connective tissue growth factor gene. Cell Growth Differ 1996; 7:469-80

39 Martinerie C, Chevalier G, Rauscher F, Jr, et al. Regulation of nov by WT1: a potential role for nov in nephrogenesis. Oncogene 1996;12:1479-92.

40 Schutze N, Lechner A, Groll C, et al. The human analog of murine cysteine-rich protein 61 is a $1 \alpha, 25$ dihydroxyvitamin D3 responsive immediate early gene in human fetal osteoblasts: regulation by cytokines, growth factors, and serum. Endocrinology 1998;139:1761-70.

41 Rivera-Gonzalez R, Petersen DN, Tkalcevic G, et al. Estrogen-induced genes in the uterus of ovariectomized Estrogen-induced genes in the uterus of ovariectomized rats and their regulation by droloxifene

42 Chung KC, Ahn YS. Expression of immediate early gene cyr61 during the differentiation of immortalized embryonic hippocampal neuronal cells. Neurosci Lett 1998;255:155-8.

43 Stanhope-Baker P, Williams BR. Identification of connective tissue growth factor as a target of WT1 transcriptional regulation. F Biol Chem 2000;275:38139-50

44 Kondo Y, Nakanishi T, Takigawa $M$, et al. Immunohistochemical localization of connective tissue growth factor in the rat central nervous system. Brain Res 1999; 834:146-51.

45 O'Brien TP, Yang GP, Sanders L, et al. Expression of cyr61, a growth factor-inducible immediate-early gene. $\mathrm{Mol} \mathrm{Cell}$ Biol 1990;10:3569-77.

46 Su BY, Cai WO, Zhang CG, et al. A developmental study of novH gene expression in human central nervous system. $C$ novH gene expression in human ce

47 Kireeva M, Latinkic B, Kolesnikova T, et al. Cyr61 and Fisp12 are both ECM-associated signaling molecules: activities, metabolism, and localization during development. Exp Cell Res 1997:233:63-77.

48 O'Brien TP, Lau LF. Expression of the growth factorinducible immediate early gene cyr61 correlates with chondrogenesis during mouse embryonic development. Cell Growth Differ 1992;3:645-54.

49 Wong M, Kireeva M, Kolesnikova T, et al. Cyr61, product of a growth factor-inducible immediate-early gene, regulates chondrogenesis in mouse limb bud mesenchymal cells. Dev Biol 1997;192:492-508

50 Hadjiargyrou M, Ahrens W, Rubin CT. Temporal expression of the chondrogenic and angiogenic growth factor CYR61 during fracture repair. $\mathcal{F}$ Bone Miner Res 2000;15: 1014-23.

51 Nakanishi T, Kimura Y, Tamura T, et al. Cloning of a mRNA preferentially expressed in chondrocytes by differential display-PCR from a human chondrocytic cell line ential display-PCR from a human chondrocytic cell line that is identical with connective tissue growth factor 206-10.

52 Shimo T, Nakanishi T, Kimura Y, et al. Inhibition of endogenous expression of connective tissue growth factor by its antisense oligonucleotide and antisense RNA suppr proliferation and migration of vascular endothelial cells. $\mathscr{F}$ Biochem 1998;124:130-40.

53 Nakanishi $T$, Nishida $T$, Shimo $T$, et al. Effects of CTGF/Hcs24, a product of a hypertrophic chondrocyte-specific gene, on the proliferation and differentiation of chondrocytes in culture. Endocrinology 2000;141:264-
54 Nishida T, Nakanishi t, Shimo T, et al. Demonstration of receptors specific for connective tissue growth factor on a hes Commun 1998;247:905-9.

55 Nishida T, Nakanishi T, Asano M, et al. Effects of $\mathrm{CTGF} / \mathrm{Hcs} 24$, a hypertrophic chondrocyte-specific gene product, on the proliferation and differentiation of osteoblastic cells in vitro. F Cell Physiol 2000;184:197-206.

56 Barbot W. DEA biologie cellulaire et moleculaire. Université Paris VI. 1997.

57 Perbal B. Caractérisation et expression du proto-oncogène nov humain dans les tumeurs de Wilms. Bull Cancer (Paris) 1994;81:957-61.

58 Yang GP, Lau LF. Cyr61, product of a growth factorinducible immediate early gene, is associated with the extracellular matrix and the cell surface. Cell Growth Differ 1991;2:351-7.

59 Martinerie C, Huff V, Joubert I, et al. Structural analysis of the human nov proto-oncogene and expression in Wilms the human nov proto-oncogene a
tumor. Oncogene 1994;9:2729-32.

60 Lopez-Bermejo A, Buckway CK, Devi GR, et al. Characterization of insulin-like growth factor-binding protein-related proteins (IGFBP-rPs) 1,2 and 3 in human prostate epithelial cells: potential roles for IGFBP-rP1 and 2 in senescence of the prostatic epithelium. Endocrinology 2000;141:4072-80.

$61 \mathrm{Li}$ WC, Martinerie C, Zumkeller W, et al. Differential expression of novH and CTGF in human

62 Babic A, Kireeva M, Kolesnikova T, et al. CYR61, a product of a growth factor-inducible immediate early gene, promotes angiogenesis and tumor growth. Proc Natl Acad Sci US A 1998:95:6355-60.

63 Babic A, Chen CC, Lau L. Fisp 12/mouse connective tissue growth factor mediates endothelial cell adhesion and migration through integrin $\alpha v \beta 3$, promotes endothelial cell survival, and induces angiogenesis in vivo. Mol Cell Biol 1999;19:2958-66.

64 Martinerie C, Viegas-Pequignot E, Van-Cong N, et al. Chromosomal mapping and expression of the human CYR61 gene in tumor cells from the nervous system. $f$ Clin Pathol: Mol Pathol 1997;50:310-17.

65 Gemini M, Schwalbe P, Scholl FA, Schufer BW. Isolation of genes differentially expressed in human primary myoblasts and embryonal rhabdomyosarcoma. Int $\mathcal{F}$ Cancer 1996;66: $571-7$.

66 Pilarsky C, Schmidt U, Eissrich C, et al. Expression of the extracellular matrix signaling molecule Cyr61 is downreguextracellular matrix signaling molecule Cyr61 is
lated in prostate cancer. Prostate 1998;36:85-91.

67 Tsai MS, Hornby AE, Lakins J, et al. Expression and function of CYR61, an angiogenic factor, in breast cancer cell lines and tumor biopsies. Cancer Res 2000;60:5603-7.

68 Frazier K, Grotendorst G. Expression of connective tissue growth factor mRNA in the fibrous stroma of mammary tumors. Int F Biochem Cell Biol 1997;29:153-61.

69 Igarashi A, Hayashi N, Nashiro K, et al. Differential expression of connective tissue growth factor gene in cutaneous fibrohistiocytic and vascular tumor. 7 Cutan Pathol 1998;25:143-8

70 Wenger C, Ellenrieder V, Alber B, et al. Expression and differential regulation of connective tissue growth factor in pancreatic cancer cells. Oncogene 1999;18:1073-80.

71 Shakunaga T, Ozaki T, Ohara N, et al. Expression of connective tissue growth factor in cartilaginous tumors. Cancer 2000;89:1466-73.

72 Kumar S, Hand AT, Connor JR, et al. Identification and cloning of a connective tissue growth factor-like cDNA from human osteoblasts encoding a novel regulator of osteoblast functions. F Biol Chem 1999;274:17123-31.

73 Fan WH, Karnovsky MJ. Activation of protein kinase C nhibits the expression of connective tissue growth factor. Biochem Biophys Res Commun 2000;275:312-21. 